Canadian

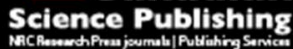

Canadian Geotechnical Journal Revue canadienne de géotechnique

\title{
Effective use of geosynthetics to increase the bearing capacity of shallow foundations
}

\begin{tabular}{|r|l|}
\hline Journal: & Canadian Geotechnical Journal \\
\hline Manuscript ID & cgj-2016-0505.R1 \\
\hline Manuscript Type: & Article \\
\hline Complete List of Authors: & $\begin{array}{l}\text { Shahin, Md. Hossain; Islamic University of Technology, Civil and } \\
\text { Environmental Engineering } \\
\text { Nakai, Teruo; Nagoya Institute of Technology; Geo-Research Institute, } \\
\text { Technical Adviser } \\
\text { Morikawa, Yukihiro; Nagoya Institute of Technology } \\
\text { Masuda, Saki; NTT West (Former Nagoya Institute of Technology) } \\
\text { Mio, Susumu; Nikken Wood Systems, Former Manager, Now Deceased }\end{array}$ \\
\hline Keyword: & $\begin{array}{l}\text { bearing capacity, finite element analysis, geosynthetics, strip foundation, } \\
\text { model test }\end{array}$ \\
\hline \multicolumn{2}{|c}{} \\
\hline
\end{tabular}




\section{Effective use of geosynthetics to increase the bearing capacity of shallow foundations}

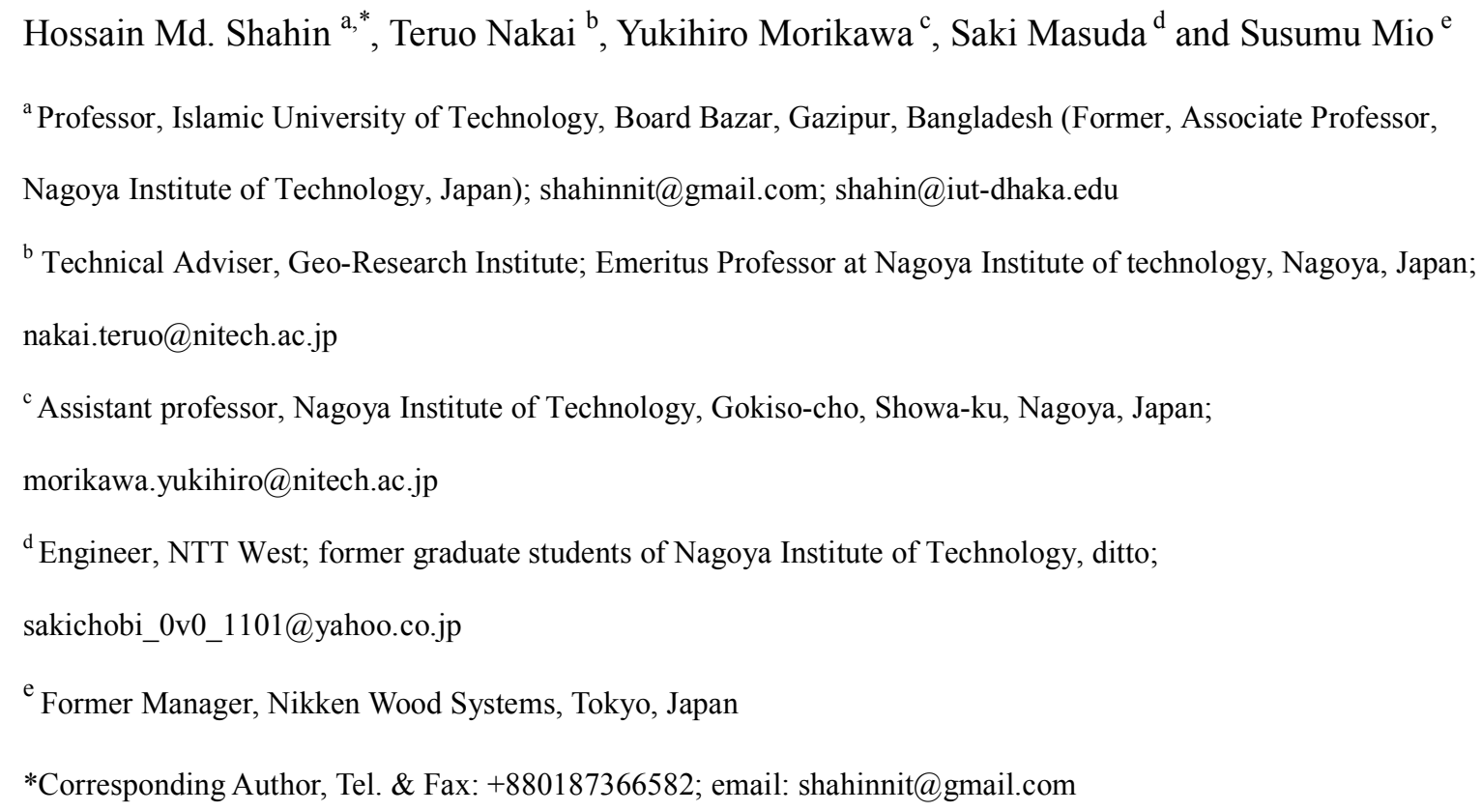

\section{ABSTRACT:}

In this research, a reinforcement mechanism for shallow foundations is determined through laboratory model tests and numerical analyses. The numerical analyses are performed with the finite element program FEMtij-2D using the elastoplastic subloading $t_{i j}$ model. The frictional behavior between the reinforcement and the ground is simulated using an elastoplastic joint element. Several tests were performed whereby the installation depth, length, roughness and fixity conditions at the edges of the reinforcement were varied. The results show that the effectiveness of the reinforcement and the bearing capacity of the reinforced ground depend on the position, length, roughness and fixity condition of the reinforcement. A significant increase in the bearing capacity can be achieved if the geosynthetics are properly placed at an optimum length with the boundary fixed to the ground. The effect of the loading position is also investigated because the load on a foundation does not always act at the center of the foundation in reality. The numerical results accurately describe the experimental results; the simulations accurately account for both the mechanical behaviors of the soil and the reinforcement and the frictional behavior between them. Therefore, the simulation technique can be used to predict the bearing capacity of 
reinforced ground.

Keywords: bearing capacity, finite element analysis, geosynthetics, model test, strip foundation

\section{INTRODUCTION}

Generally, ground with soft soil causes difficulties during the construction of large structures due to the insufficient bearing capacity of the soil, which is associated with excessive settlement of the structure. Ground improvement and replacement using good-quality soils are commonly employed to increase the bearing capacity of soft soils at certain locations. However, these processes are expensive and time consuming. Moreover, these methods can restrict workability during construction. In urban housing, the use of cement to improve the ground is particularly problematic because of increased construction costs. When replacing existing soft soils with good quality soils, temporary structures must be installed, such as sheet piles, retaining walls, and struts, which cause difficulties in building the main structure. Therefore, this research focuses on using geosynthetics to reinforce the ground to reduce ground deformation and to increase the bearing capacity of the ground. In recent years, many researchers have specified the base reinforcement technique as a solution to increase the bearing capacity of soft ground using the tensile strength of the reinforcement (Omar et al. (1993), Khing et al. (1993), Yetimoglu et al. (1994), Patra et al. (2005), Latha and Somwanshi (2009), Lovisa et al. (2010), Boushehrian et al. (2011), Alamshahi and Hataf (2009), Cicek et al. (2015)). The reinforcement used as geosynthetics consists of fiber materials that can withstand tensile forces acting upon the soils from the upper surcharge. The benefit of geosynthetic reinforcement for ground improvement has been confirmed in field-scale experiments on square footings by Adams and Collin (1997). Michalowski (2004) investigated the limit loads on reinforced foundation soils through several limit analyses and recommended that a reinforcement length of four times the footing width is required to ensure the mobilization of a considerable force in the reinforcement. Abu-Farsakh et al. (2008), Ghazavi and Lavasan (2008), 
Radhey et al. (2009), Lavasan and Ghazavi (2012) showed that the inclusion of geogrid reinforcements results in increasing the soil's bearing capacity and reducing the footing settlement. Authors checked the performance of interfering footings on soil reinforced with geosynthetics in Chiba, Japan. However, if a structure is nearby, it is impossible to lay reinforcement with a length that is four fold that of the footing width. In this research, the optimal footing length of reinforcement is determined.

In practice, geosynthetics are installed under building foundations. The edges of the reinforcing members are affixed to the ground by hooks to increase the bearing capacity. This construction method has already proven effective during a tremor of the Great East Japan Earthquake on March 11, 2011. Generally, the tension of the reinforcing member determines the increased bearing capacity of the ground. However, the reinforcing effect with geosynthetics is neither a direct process of ground improvement nor a process of increasing ground strength. Therefore, at present, evaluation is extremely difficult. As stated before, the reinforcing effect can only be achieved when tension develops in the reinforcing members, which depends on the extent of the tensile force in the geosynthetics.

The numerical analyses in this study were performed with the finite element program FEMtij-2D using the elastoplastic subloading $t_{i j}$ model (Nakai and Hinokio 2004; Nakai 2012). The validity of the model has already been verified in previous research (Nakai et al. 2009, 2010; Shahin et al. 2011, 2013). This model can describe the typical stress deformation and strength characteristics of soils, such as the influence of the intermediate principal stress, stress path dependency of plastic flow and the density and/or confining pressure.

\section{DESCRIPTION OF MODEL TESTS}

Fig. 1 shows a schematic diagram of the 2D model test apparatus. The model ground is $100 \mathrm{~cm}$ in width and $50 \mathrm{~cm}$ in height. Aluminum rods $5 \mathrm{~cm}$ in length with diameters of 1.6 and $3.0 \mathrm{~mm}$ and a 
mix ratio of $3: 2$ by weight were used as the model ground (unit mass weight of $20.4 \mathrm{kN} / \mathrm{m}^{3}$ ), which exhibits essentially the same mechanical characteristics of sandy soil. An aluminum plate was placed at the ground surface to simulate the bearing capacity of a strip (flat) foundation. Fig. 2(a) shows a model of the foundation. The foundation is $120 \mathrm{~mm}$ in width and $35 \mathrm{~mm}$ in height. Sandpaper was attached at the bottom of the foundation to create surface friction between the foundation and the ground. The vertical load was applied at the center of a strip foundation (width of $\mathrm{B}=12 \mathrm{~cm}$ ) using a motor. A slider, which permits horizontal movement of the loading rod, and a load cell, which measures the magnitude of the load, were installed in the loading system. The model test to prototype scale ratio was 1:100.

Fig. 2(b) shows a typical model of reinforcement material. The tracing paper with almost no bending stiffness was used as a reinforcement material and was placed underneath the foundation, where the installation depth (D) was varied. In series 1 , four sets of reinforcement lengths, $\mathrm{L}=36$ $\mathrm{cm}(\mathrm{L} / \mathrm{B}=3), \mathrm{L}=24 \mathrm{~cm}(\mathrm{~L} / \mathrm{B}=2), \mathrm{L}=12 \mathrm{~cm}(\mathrm{~L} / \mathrm{B}=1)$, and $\mathrm{L}=6 \mathrm{~cm}(\mathrm{~L} / \mathrm{B}=0.5)$, are considered. Two types of frictional conditions of the geosynthetics were used - the first type used aluminum rods with diameters of $1.6 \mathrm{~mm}$ that were glued at both sides of the tracing paper to roughen the surface of the reinforcement (frictional angle between the ground and the reinforcement $\delta=20^{\circ}$ which was obtained from laboratory experiment), and the second type considered smooth reinforcement, where the aluminum rods were not glued to tracing paper (frictional angle between the ground and the reinforcement $\delta=8^{0}$ ). By changing the installation depth (D), length (L) and skin friction coefficient $(\delta)$ of the reinforcements, 13 tests patterns were considered in series 1 , which are listed Table 1.

In series 2, the edges of the reinforcement were kept fixed with the ground, where the reinforcement was placed at a depth of $\mathrm{D} / \mathrm{B}=0.5$. Here, four sets of reinforcement lengths, $\mathrm{L}=36$ $\mathrm{cm}(\mathrm{L} / \mathrm{B}=3), \mathrm{L}=24 \mathrm{~cm}(\mathrm{~L} / \mathrm{B}=2), \mathrm{L}=12 \mathrm{~cm}(\mathrm{~L} / \mathrm{B}=1)$, and $\mathrm{L}=6 \mathrm{~cm}(\mathrm{~L} / \mathrm{B}=0.5)$, were considered and are the same as those in series 1 . An aluminum plate $3 \mathrm{~cm}$ in length was attached at each end of 
the reinforcement. The plate moved with the surrounding ground when a load was applied. The test patterns of this series are listed in Table 2. Here, the installation depth was $\mathrm{D} / \mathrm{B}=1 / 4$.

Table 3 presents the patterns of experiments in series 3. The reinforcement was set underneath the foundation at different installation depths (D). Five sets of reinforcement depths were considered: $\mathrm{D} / \mathrm{B}=0.00,0.05,0.10,0.20$ and 0.40 . The reinforcement length (L) was $144 \mathrm{~mm}$, which is 1.2 times the width of the foundation $(B=120 \mathrm{~mm})$ as shown in Fig. 2(b). The fixity condition of the geosynthetics was imposed by setting an aluminum plate at both edges of the reinforcement. An aluminum plate with a thickness of $2 \mathrm{~mm}$, a height of $15 \mathrm{~mm}$, and a width of $50 \mathrm{~mm}$ was used to model the fixed boundary condition of the reinforcement, which was projected from the tracing paper (geosynthetics), where the sizes of the upper part and lower part were 5 and $10 \mathrm{~mm}$, respectively. The plate moves with the surrounding ground as the load is applied. In practice, the load on a large structure does not always act at the center of the foundation. Therefore, in this research, the effectiveness of the reinforcement has been investigated for the two different loading positions, where the load was applied at the center (concentric loading) and at an eccentricity of $\mathrm{e}=1 / 4 \mathrm{~B}$ (eccentric loading).

The vertical displacement and rotation of the foundation were measured using two displacement transducers installed at the two edges of the foundation plate. Photographs were taken during the experiments and were later used as input data to determine ground movements with a program based on the particle image velocimetry (PIV) technique (Adrian 1991).

\section{DESCRIPTION OF NUMERICAL ANALYSES}

Numerical analyses were conducted and used the same scale as the 2D model tests.

Two-dimensional finite element analyses were performed using the FEMtij-2D program, which was developed in our laboratory. Fig. 3 shows a typical mesh used in the numerical analyses. Isoparametric four-node elements were used for the soil elements, and elastic beam elements were used to simulate the reinforcements. The frictional behavior between the reinforcement and 
aluminum rods and the foundation and aluminum rods was modeled using an elastoplastic joint element (Nakai 1985). A brief description of the model of elastoplastic joint element is illustrated in APPENDIX A1. The friction angle between the reinforcement and the aluminum rods was determined by the sliding tests ( $\delta=20^{\circ}$ for rough reinforcements). In the sliding test, the reinforcement was laid on the ground consisting mass of aluminum rods. Then pulled the reinforcement putting variable weights on the tracing paper. From the graph of weight verses pulling force, friction angle was measured. The friction angle between the foundation and the soil was $\delta=15^{\circ}$. Both vertical sides of the mesh were free in the vertical direction, and the bottom face was kept fixed. In the numerical analyses, the elastoplastic subloading $t_{\mathrm{ij}}$ model (Nakai and Hinokio 2004; Nakai 2012) was used as a constitutive model for the ground. This model can describe the typical stress, deformation and strength characteristics of soils, such as the influence of intermediate principal stress, the influence of the stress path dependency of plastic flow and the influence of density and/or confining pressure. The same parameters of the aluminum rods (Shahin et al. 2011) were used for the ground materials. The parameters of the aluminum rods are listed in Table 4. The parameters are fundamentally the same as those of the Cam clay model, except for the parameter $a$, which is responsible for the influence of the density and the confining pressure. The parameter $\beta$ represents the shape of the yield surface. The parameters can easily be obtained from traditional laboratory tests. Fig. 4 shows the results of the biaxial tests for the mass of aluminum rods used in the model tests. From the stress-strain behavior of the element tests simulated with the subloading $t_{i j}$ model, it can be observed that this model can express the dependency of stiffness, strength and dilatancy on the density and on the confining pressure. It is clear that the strength and deformation behavior are extremely similar to those of medium dense sand. The dotted lines represent the numerical results for a confining pressure $1 / 100$ that of the confining pressure in the experiments. The initial stress levels of the ground were calculated by applying the body forces due to the self-weight $\left(\gamma=20.4 \mathrm{kN} / \mathrm{m}^{3}\right)$, beginning from a negligible 
confining pressure $\left(\mathrm{p}_{0}=9.8 \times 10-6 \mathrm{kPa}\right)$ and an initial void ratio of $\mathrm{e}=0.35$. After the self-weight consolidation, the void ratio of the ground was between 0.28 and 0.30 . The value of $\mathrm{K}_{0}$, which was derived from the simulation of the self-weight consolidation, was between 0.70 and 0.73 . Fig. 5 shows the computed results of the elastoplastic joint element (Nakai 1985), which shows that almost no slippage $\left(\mathrm{w}_{\mathrm{s}}\right)$ was observed at the interface until the ratio of the shear to normal stresses $\left(\mathrm{P}_{\mathrm{s}} / \mathrm{P}_{\mathrm{n}}\right)$ reached a value equal to $\tan \delta$. After $\mathrm{P}_{\mathrm{s}} / \mathrm{P}_{\mathrm{n}}$ becomes $\tan \delta$, slippage occurs while $\mathrm{P}_{\mathrm{s}} / \mathrm{P}_{\mathrm{n}}$ maintains a value equal to $\tan \delta$. Therefore, the interface model can describe the mechanical behavior of the interface boundary. The frictional angles between the reinforcement and soil and the foundation and soil, which were measured in the experiments, were used in the numerical analyses. A bending stiffness (EI) of $1.34 * 10^{-7} \mathrm{~N}-\mathrm{m}^{2} / \mathrm{m}$ and an axial stiffness of $1.34 * 10^{3} \mathrm{~N} / \mathrm{m}$ were used for the reinforcements.

\section{RESULTS AND DISCUSSIONS}

\section{Influence of installation depth of the reinforcement: Series 1}

Fig. 6 shows the observed and computed bearing capacity for different installation depths, where the reinforcement length is $24 \mathrm{~cm}$. The vertical axes represent the vertical load $\mathrm{q}_{\mathrm{v}}$, which is divided by $\gamma \mathrm{B} / 2$, and the abscissa represents the normalized vertical displacement, which is normalized by the width of the foundation (B). In this research, the ground consists of mass of aluminum rods which does not have cohesion. Therefore, as the term $2 \mathrm{q}_{\mathrm{v}} / \mathrm{B}$ represents the bearing capacity factor $N_{\gamma}$ The figures also show the results when no reinforcement was used. The influence of the reinforcement cannot be expected if the installation depth is greater than a certain value (D/B is greater than $1 / 2)$. The results are very similar to the results found in the reference of Michalowski (2004). In addition, when the reinforcement is placed on the ground surface slightly below the foundation, the reinforcements exhibit almost no effect, except for the effect of the friction coefficient of the foundation. The numerical analyses agree well with results of the influence of the installation depth from the model tests. 
Fig. 7 represents the bending moment distributions of the reinforcement and axial force distributions. It can be observed that the bending moment is almost zero in all cases, as expected. However, either the central part of the reinforcement exhibits higher distribution of the axial force or the value of the axial force in the central part of the reinforcement becomes remarkably high where the effect of the reinforcement exists $(\mathrm{D} / \mathrm{B}=1 / 4)$. Fig. 8 shows the observed and computed deviatoric strain distributions of the ground as the load approaches peak strength (for the model test, the peak strength occurs at $\mathrm{v} / \mathrm{B}=0.04$, whereas it occurs at $\mathrm{v} / \mathrm{B}=0.1$ in the analysis). The distribution of the deviatoric strain in the model tests were obtained from the simulation of the particle image velocimetry (PIV) technique, which captured two images before and after loading. The topmost figure represents the results of the ground without reinforcement, where it can be seen that where the reinforcement effect is the greatest $(\mathrm{D} / \mathrm{B}=1 / 8,1 / 4)$, a zone of large deviatoric strain spreads vertically below the foundation compared with that with no reinforcement. For $\mathrm{D} / \mathrm{B}=1 / 2$ and 1 , where there is essentially no reinforcement effect, the zone of large deviatoric strain does not spread vertically below the foundation. Particularly for $\mathrm{D} / \mathrm{B}=1.0$, the distribution of the deviatoric strain is essentially the same as in the case with no reinforcement; in this case, the reinforcement does not improve the ground. The computed results agree well with the differences in the deviatoric strain distribution observed in the model tests.

\section{Influence of reinforcement length: Series 1}

The influence of reinforcement was investigated for several reinforcement lengths at a constant installation depth $(\mathrm{D} / \mathrm{B}=1 / 4)$. The graphs that were presented in the previous section, which were similar, for different installation depths will be shown in this section. Fig. 9 shows the relations of the load displacement for different reinforcement lengths, where it can be observed that even for $\mathrm{L}=6 \mathrm{~cm}(\mathrm{~L} / \mathrm{B}=1 / 2)$, the reinforcement exhibits several effects on the bearing capacity of the ground. However, almost no differences in the reinforcement effects on the bearing capacity were observed for L/B values greater than 2.0 in model tests and 1.0 in analysis. The numerical 
analyses agree well with the results of the model tests.

Fig. 10 presents the distributions of the bending moment and axial force of the reinforcements. Essentially, the same axial force distribution is observed for L/B values greater than 1.0, which describes the aforementioned reinforcement mechanism. Fig. 11 shows the distributions of a deviatoric strain in the ground similar to that shown in Fig. 8 (see the top graphs in Fig. 8 for the results for when no reinforcement was used and with $\mathrm{L} / \mathrm{B}=2.0$ ). As the reinforcement effect increases, a zone of large deviatoric strain spreads vertically below the foundation. The same reinforcement effect is expected when $\mathrm{L} / \mathrm{B}$ is greater than 1.0.

\section{Influence of friction angle of reinforcement: Series 1}

In the previous sections, the friction angle $(\delta)$ was $20^{\circ}$. In this section, the effects of the friction angle will be discussed based on the same condition illustrated in Figs. $6-8$ ( $\mathrm{L}=24 \mathrm{~cm})$, except a different value of the friction angle $\left(\delta=8^{0}\right)$ is used. Here, the surface of the reinforcement (tracing paper) is smooth, i.e., no aluminum rod is glued to the tracing paper. The relation for the load displacement is shown in Fig. 12. Fig. 13 illustrates the computed distributions of the bending moment and the axial force. Fig. 14 shows the distributions of the deviatoric strain in the ground (see Fig. 8 for the results when no reinforcement was used). Comparing Fig. 6 with Fig. 12 reveals that at the smaller friction angle, the reinforcement effect decreases, even for the same reinforcement stiffness. As shown in Fig. 12, when the reinforcement is installed at an appropriate depth (e.g., $\mathrm{D} / \mathrm{B}=1 / 8)$, the bearing capacity of the ground increases, even with a smooth reinforcement. The opposite effect can also be seen (for example, for $\mathrm{D} / \mathrm{B}=1 / 2$ ), depending on the installation depth, in the case of a smaller friction angle. Almost no reinforcement effect is observed when $\mathrm{D} / \mathrm{B}=1$ for both types of friction angles. The numerical analyses can accurately predict the phenomenon of the reinforcement effect for different friction angles.

From Fig. 13, it can be observed that the axial force for $\mathrm{D} / \mathrm{B}=1 / 2$ is smaller than that $\mathrm{D}$ / $\mathrm{B}=1$; therefore, a negative reinforcement effect for $\mathrm{D} / \mathrm{B}=1 / 2$ can be speculated. From Figs. 7,10 and 13, 
it can be observed that although the axial force is smaller near the edges, it increases at the central part of the reinforcement where the reinforcement effect exists. The deviatoric strain develops to a wider, deeper region, even for the smooth reinforcement when $\mathrm{D} / \mathrm{B}=1 / 8$, where the reinforcement effect can be observed (Fig. 14). However, for the smooth reinforcement at $\mathrm{D} / \mathrm{B}=1 / 2$, where a negative reinforcement effect occurs, the region of the larger deviatoric strain is shallower than that when no reinforcement is used. This result is because slippage occurs on the top surface of the reinforcement before developing a zone of shear strain vertically below the foundation. Hence, a larger deviatoric strain is concentrated near the ground surface. The numerical analyses can accurately reproduce the mechanism of the deviatoric strain distribution of the model tests.

Influence of the fixity conditions of reinforcement: varying the reinforcement length (Series 2)

In series 1 , it was found that when the reinforcement depth is between $D / B=1 / 8$ to $D / B=1 / 2$, the reinforcement effect is at its maximum. Therefore, in this series, the installation depth of $D / B=1 / 4$ is used for all tests. Fig. 15 shows the observed bearing capacity for different reinforcement lengths, where (a) shows the results of the reinforcement where the end is free, and (b) shows the results of the fixed-end reinforcement. Fig. 16 shows the computed bearing capacity that corresponds to the observed bearing capacity illustrated in Fig. 15. The vertical axes represent the normalized vertical load, and the abscissa represents the normalized vertical displacement. The figures also show the load displacement curve of the ground without reinforcement. Under the free end condition (Fig. 15(a)), a similar reinforcement effect on the bearing capacity of the ground is observed at $\mathrm{L} / \mathrm{B}$ values of less than or equal to 2 . When the end of the reinforcement is fixed, the reinforcement with $\mathrm{L} / \mathrm{B}=1$ maximizes the bearing capacity of the ground. The overall bearing capacity is larger under the fixed-end conditions compared to that of the free end condition. The numerical analyses (Fig. 16) agree well with the results of the model tests, which include the maximum bearing capacity of the model ground.

Figs. 17(a) and 17(b) represent the distributions of the bending moment and axial force of the 
reinforcements for the free and fixed-end conditions, respectively. It can be observed that the bending moment is almost zero in all cases, which is expected. However, either a large range of larger axial forces is distributed in the central part of the reinforcement or the value of the axial force in the central part of the reinforcement becomes remarkably high where the reinforcement effect is observed. For $\mathrm{L} / \mathrm{B}=1$ under the fixed-end condition, which is when the reinforcement effect is significantly increased, a large tensile force is observed in the central part of the reinforcement, with a wider region compared with those of the other cases.

Fig. 18 illustrates the observed and computed deviatoric strain distributions of the ground while the load approaches peak strength (for the model test, the peak strength occurs at $\mathrm{v} / \mathrm{B}=0.06$, whereas it occurs at $\mathrm{v} / \mathrm{B}=0.1$ in the analysis) for the fixed-end reinforcement $(\mathrm{L} / \mathrm{B}=1)$. The distribution of the deviatoric strain, where no reinforcement is used in the ground, is illustrated in series 1 (Fig. 8), and that for the end free reinforcement $(\mathrm{L} / \mathrm{B}=1)$ is illustrated in Fig. 11 for $\mathrm{D} / \mathrm{B}=1 / 4$. It can be observed that where the reinforcement effect is the most significant (Fig. 18), a zone of larger deviatoric strain spreads vertically below the foundation without significantly spreading in the horizontal direction. The tension of the reinforcement, which develops due to the loading, increases the confining stress in the ground directly beneath the foundation. Hence, the ground above the reinforcement and directly underneath the foundation, which includes the reinforcement, acts as a unit body, which increases the bearing capacity to a value similar to that of an embedded foundation. The numerical analyses perfectly predict the deviatoric strain distribution both for the reinforced ground and the ground without reinforcement.

\section{Influence of fixity conditions of reinforcement - varying the installation depth: Series 3}

\section{Concentric loading}

Figs. 19(a) and (b) show the observed and computed bearing capacity for different installation depths under the concentric loading condition where the reinforcement length is $14.4 \mathrm{~cm}$ $(\mathrm{L} / \mathrm{B}=1.2)$. The vertical axes represent the normalized vertical load, and the abscissa represents the 
normalized vertical displacement. The figures also show the load displacement curve of the ground without reinforcement. It can be observed from the figures that the bearing capacity increases with installation reinforcement depth at $\mathrm{D} / \mathrm{B}=0.05,0.10$, and 0.20 compared with that with no reinforcement. In addition, essentially the same reinforcement effect exists when the installation depth is between $\mathrm{D} / \mathrm{B}=0.05$ and 0.20 . However, the reinforcement will not have an effect when the installation depth is greater than a certain depth $(\mathrm{D} / \mathrm{B}$ is greater than or equal to 0.40). Similarly, when the reinforcement is placed on the ground surface slightly below the foundation, almost no reinforcement effect is observed, except for on the coefficient of friction of the foundation; this behavior is similar to that with no reinforcement. The results agree with the results of series 1 , where it was found that when the reinforcement depth is between $\mathrm{D} / \mathrm{B}=1 / 8$ and $\mathrm{D} / \mathrm{B}=1 / 2$, the reinforcement effect is maximized. Therefore, it can be concluded that when the installed reinforcement is deeper than the ground surface and when it is situated in a certain range, the reinforcement effect can easily be achieved. When the installed reinforcement depth is shallower, a tensile force develops in the reinforcement due to the load application. Fig. 19(b) shows the computed bearing capacity for different installation depths for concentric loadings. Compared with the observed results, the numerical analyses slightly overestimated the bearing capacity of the model tests. However, if compared with the results when no reinforcement was used, the bearing capacity for the reinforcement at $\mathrm{D} / \mathrm{B}=0.05,0.10$ and 0.20 increases similar to that of the model tests. In addition, in the cases of reinforcement placed at the surface and at depths deeper than $\mathrm{D} / \mathrm{B}=0.40$, there is almost no reinforcement effect. Therefore, it can be concluded that the analysis results of the behavior of the reinforcement effect agree well with the observed results.

Fig. 20 illustrates the observed and computed deviatoric strain distributions of the ground as the load approaches peak strength. The upper figure represents the results when no reinforcement was used. It can be observed that where the reinforcement effect exists, for the reinforcement at 
$\mathrm{D} / \mathrm{B}=0.10$, a zone of larger deviatoric strain spreads vertically below the foundation and becomes widely distributed compared with that with no reinforcement. For an installation depth of $\mathrm{D} / \mathrm{B}=0.4$, deviatoric strain develops within a narrower zone, and thus, the bearing capacity of the ground does not increase. The computed results agree well with the differences in the deviatoric strain distribution that were observed in the model tests at different installation depths.

\section{Eccentric loading}

Fig. 21(a) shows the observed bearing capacity for different installation depths under the eccentric loading condition for the same test patterns as those under concentric loading. Here, the load was applied at $2 \mathrm{e} / \mathrm{B}=0.5$, i.e., at the $1 / 4^{\text {th }}$ point of the strip foundation. The vertical axes and the abscissa are the same as those in Fig. 19. The figures also show the results of the measurements for ground without reinforcement. It can be observed that the bearing capacity for eccentric loading is smaller than that for concentric loading (as illustrated in Fig. 19). As shown in Fig. 21(a), the bearing capacity increased for installation depths of $\mathrm{D} / \mathrm{B}=0.05,0.10$, and 0.20 compared to that with no reinforcement, and the reinforcement influence cannot be expected when the installation depth is greater than a certain depth (D/B is greater or equal to 0.40$)$. These results are similar to those under the concentric loading condition. Consequently, it can be concluded that when the reinforcement is installed at depths greater than the ground surface and when it is situated in the range of influence of the loading on the foundation, the reinforcement effect can be achieved even under the eccentric loading condition.

Fig. 21(b) shows the computed bearing capacity at different installation depths for the eccentric loading condition. Compared with the observed results, the numerical analyses slightly overestimate the bearing capacity of the model tests. However, when compared with the results when no reinforcement was used, the bearing capacity of the reinforcements at $\mathrm{D} / \mathrm{B}=0.05,0.10$ and 0.20 increased similarly to those from the model tests. In addition, in the cases of reinforcement at the surface and at depths greater than $\mathrm{D} / \mathrm{B}=0.40$, there was essentially no 
reinforcement effect. Therefore, it can be said that the analyses simulate a reinforcement effect behavior that is similar to that of the observed results. The numerical analyses can not only simulate the results of the model tests for concentric loading, but also simulate the results of the model tests for eccentric loading.

Fig. 22(a) shows the observed relation between the rotations of the strip foundation and the normalized vertical load under the eccentric loading condition. Because a uniform load was not applied to the foundation under the eccentric loading condition, it is important to reduce the magnitude of the rotation, which occurs at the time of construction. As shown in Fig. 22(a), the rotation of the foundation begins at a higher load when the reinforcement is installed at $\mathrm{D} / \mathrm{B}=0.05$ and 0.10 due to the reinforcement effect compared to that with no reinforcement, i.e., the foundation can bear a higher load without rotating if it is properly reinforced beneath the foundation. However, the load bearing capacity without any rotation of the foundation is smaller when the reinforcement is installed at $D / B=0.20$ compared with the other two cases $(D / B=0.05$ and 0.10$)$. In contrast, behavior similar to that with no reinforcement is observed when the reinforcement is installed at $\mathrm{D} / \mathrm{B}=0.40$. It can be concluded that the rotation angle of the foundation decreases in the reinforced ground when the reinforcement is at $\mathrm{D} / \mathrm{B}=0.05,0.10$ and 0.20. The tendency of the reinforcement effect to reduce the rotation angle of the foundation is similar to that shown in the relation between the bearing capacity and the displacement, as described before.

Fig. 22(b) shows the results of the numerical analyses corresponding to the model tests shown in Fig. 22(a). Compared with the observed results, the numerical analyses slightly overestimate the rotation during the initial stage. However, if compared with the results when no reinforcement is used, the rotation of the foundation decreases when the reinforcement is installed at $\mathrm{D} / \mathrm{B}=0.05$, 0.10 and 0.20 , which is similar to that of the model tests. When reinforcement is installed at $\mathrm{D} / \mathrm{B}=0.20$, the reinforcement effect of reducing the rotation of the foundation is smaller than those 
of the other two cases $(\mathrm{D} / \mathrm{B}=0.05$ and 0.10$)$, which is similar to the model tests. Similarly, the analyses do not show any reinforcement effect on the rotation of the foundation for the case when the installation depth is $\mathrm{D} / \mathrm{B}=0.40$. Therefore, it can be concluded that there is good agreement between the computed and observed results for the rotation of the foundation. Thus, differential settlements can be controlled under eccentric loading conditions by installing geosynthetics under the foundation at an appropriate depth.

Fig. 23 illustrates the observed and computed deviatoric strain distributions of the ground while the load approaches peak strength, which occurs at $\mathrm{v} / \mathrm{B}=0.03$ for the model test, at $\mathrm{v} / \mathrm{B}=0.06$ in the analysis with no reinforcement, and at 0.10 when the reinforcement is installed at $\mathrm{D} / \mathrm{B}=0.10$ and 0.40. The topmost figure represents the results when no reinforcement is installed. It can be observed that even in the case of eccentric loading where there is a reinforcement effect, for reinforcement at $\mathrm{D} / \mathrm{B}=0.10$, a zone of larger deviatoric strain spreads vertically below the foundation and is widely distributed compared to the zone when no reinforcement is used. For the reinforcement installation depth of $\mathrm{D} / \mathrm{B}=0.4$, deviatoric strain develops in a narrower zone, similar to that with concentric loading. The computed results agree well in terms of the differences in the deviatoric strain distributions compared to those observed in the model tests under eccentric loading conditions.

\section{CONCLUSIONS}

The bearing capacity of soil reinforcement using geosynthetics was investigated with laboratory model tests and with the corresponding numerical analyses. The present research can be summarized as follows:

\section{Series 1:}

The effectiveness of the reinforcement primarily depends on the position of the reinforcement and its skin friction coefficient. Essentially, no extra reinforcement effect occurs when it is placed deeper than a certain depth $(\mathrm{D} / \mathrm{B}=1 / 2)$. A moderate reinforcement effect occurs when the 
reinforcement has a smaller skin friction coefficient, except at $\mathrm{D} / \mathrm{B}=1 / 2$, where no reinforcement effect is expected. A reinforcement length greater than the width of the foundation is preferable for attaining the reinforcement effect in the case of free ended geosynthetics. A wider, deeper region of deviatoric strain was confirmed when the reinforcement effect occurred. The maximum tensile force developed at the central part of the reinforcement when a significant reinforcement effect existed. The results obtained from the numerical analyses are in good agreement with the results of the model tests under every condition examined, e.g., for the different reinforcement lengths, installation depths and skin friction coefficients of the reinforcement.

\section{Series 2:}

When the reinforcement end is fixed to the ground, the reinforcement with around $\mathrm{L} / \mathrm{B}=1$ results in the maximum bearing capacity. The overall bearing capacity under the fixed end condition is larger than that under the free end condition for the reinforcement. A wider, deeper region of deviatoric strain was confirmed when the reinforcement effect occurred. The value of the axial force in the central part of the reinforcement becomes remarkably high where the reinforcement effect exists. The results obtained from the numerical analyses are in good agreement with the results of the model tests in all patterns. Therefore, if the reinforcement laid in an effective depth it increases the load bearing capacity of the ground to the maximum value even with the same length of foundation which has an extra advantage in installation in the ground.

\section{Series 3:}

The effectiveness of reinforcement primarily depends on the position of the reinforcement, where the maximum reinforcement effect can be achieved when it is installed between $\mathrm{D} / \mathrm{B}=0.05$ and $\mathrm{D} / \mathrm{B}=0.20$ under the fixed end condition. However, under the eccentric loading condition, the reinforcement effect decreases when the installation depth of the reinforcement is $\mathrm{D} / \mathrm{B}=0.20$. Furthermore, if the reinforcement is installed at a depth of $\mathrm{D} / \mathrm{B}=0.40$ or greater, the reinforcement effect is not achieved. If the reinforcement is situated in the range of influence of the loading, the 
reinforcement effect can be achieved even under the eccentric loading condition. By installing geosynthetics under the foundation at an appropriate depth, differential settlements can be controlled under the eccentric loading condition, which is important in field construction.

The results obtained from the numerical analyses are in good agreement with the results of the model tests in all patterns. The laying position is one of the most important factors to be considered in reinforced ground for increasing bearing capacity and reducing settlement of foundation. Frictional angle between soils and geosynthetics is an important parameter which should be carefully taken into account. It can be concluded that if the mechanical properties of the ground material and reinforcement material and the skin friction coefficient of the reinforcement are appropriately considered and if the soil reinforcement is treated as an interaction problem between the soil and the structure (soil and reinforcement), the reinforcement mechanism can be properly explained with model tests and numerical simulations.

\section{ACKNOWLEDGEMENTS}

The authors are very much grateful to Tomoya Takeda and Ryou Suzuki, graduate student of Nagoya Institute of Technology, for their contributions in the model tests and the numerical simulations.

\section{References:}

Abu-Farsakh, M., Chen, Q., Sharma, R., and Zhang, X. 2008. Large-Scale Model Footing Tests on Geogrid Reinforced Marginal Embankment Soil, ASTM Geotechnical Testing Journal, 31(5), 413-423.

Adams, M. T., and Collin, J. G., 1997. Large model spread footing load tests on geosynthetic reinforced soil foundations. J. of Geotech. Geoenviron. Eng., 123(1), 66-72.

Adrain, R. J. 1991. Particle imaging techniques for experimental fluid mechanics. Ann. Rev. Fluid 
Mech., 23, 261-304.

Alamshahi, S., and Hataf, N. 2009. Bearing capacity of strip footings on sand slopes reinforced with geogrid and grid-anchor, Geotextiles and Geomembranes 27 (3), 217-226.

Boushehrian, A.H., Hataf, N., and Ghahramani, A. 2011. Modeling of the cyclic behavior of shallow foundations resting on geomesh and grid-anchor reinforced sand, Geotextiles and Geomembranes 29 (3), 242-248.

Cicek, E., Guler, E., and Yetimoglu, T. 2015. Effect of reinforcement length for different geosynthetic reinforcements on strip footing on sand soil, Soils and Foundations, 55(4), 661-677.

Ghazavi, M., and Lavasan, A. A. 2008. Interference effect of shallow foundations constructed on sand reinforced with geosynthetics. Geotextiles and Geomembranes, 26(5), 404-415.

Hashiguchi, K. 1980. Constitutive equation of elastoplastic materials with elasto- plastic transition. J. of Applied Mech., ASME, 102(2), 266-272.

Khing, K. H., Das, B. M., Puri, V. K., Cook, E. E., and Yen, S. C. 1993. Bearing capacity of strip foundation on geogrid-reinforced sand. Geotextile and Geomembranes, 12(4), 351-361.

Latha, G.M., and Somwanshi, A. 2009. Effect of reinforcement form on the bearing capacity of square footings on sand. Geotextiles and Geomembranes, 27 (6), 409 - 422.

Lavasan, A. A., and Ghazavi, M. 2012. Behavior of closely spaced square and circular footings on reinforced sand. Soils and Foundation, 52(1):160-167.

Lovisa, J., Shukla, S.K., and Sivakugan, N. 2010. Behaviour of prestressed geotextile-reinforced sand bed supporting a loaded circular footing. Geotextiles and Geomembranes, 28(1), 23 32.

Michalowski, R. L. 2004. Limit Loads on Reinforced Foundation Soils. J. of Geotech. Geoenviron. Eng., 130 (4), $381-39$.

Nakai, T. 1985. Finite element computations for active and passive earth pressure problems of 
retaining wall. Soils and Foundations, 25(3), 98-112.

Nakai, T. 2012. Constitutive Modeling of Geomaterials: Principles and Applications, 1st ed. Boca Raton, London, New York: CRC Press.

Nakai, T., and Hinokio, M. 2004. A simple elastoplastic model for normally and over consolidated soils with unified material parameters. Soils and Foundations. 44(2), 53-70.

Nakai, T., and Matsuoka, H. 1986. A generalized elastoplastic constitutive model for clay in three-dimensional stresses. Soils and Foundations, 26(3), 81-98.

Nakai, T., and Mihara, Y. 1984. A new mechanical quantity for soils and its application to elastoplastic constitutive models. Soils and Foundations, 24(2): 82-94.

Nakai, T., Shahin, H.M., Watanabe, A., and Yonaha, S. 2009. Reinforcing mechanism of Geosynthetics on bearing capacity problems - model tests and numerical simulations. Proc. of the $17^{\text {th }}$ Int. Con. on Soil Mech. and Geotech. Eng., Egypt, October, pp. 917-920

Nakai, T., Shahin, H.M., Zhang, F., Hinokio, M., Kikumoto, M., Yonaha, S., and Nishio, A. 2010. Bearing capacity of reinforced foundation subjected to pull-out loading in 2D and 3D conditions. Geotextiles and Geomembranes, 28(3), $268-280$.

Omar, M. T., Das, B. M., Puri, V. K., and Yen, S. C. 1993. Ultimate bearing capacity of shallow foundations on sand with geogrid reinforcement. Can. Geotech. J., 30, 545-549.

Patra, C.R., Das, B.M., and Atalar, C. 2005. Bearing capacity of embedded strip foundation on geogrid-reinforced sand. Geotextiles and Geomembranes, 23(5), 454 - 462.

Radhey, S., Qiming, C., Abu-Farsakh, M., and Sungmin, Y. 2009. Analytical modeling of geogrid reinforced soil foundation. Geotextiles and Geomembranes, 27(1), 63-72.

Shahin, H.M., Nakai, T., Morikawa, Y., Masuda, S, Mio, S., and Sugiyama, H. 2013. Bearing capacity of reinforced ground considering fixity conditions of geosynthetics. Advance in Foundation Engineering, December, pp. 385-392.

Shahin, H.M., Nakai, T., Zhang, F., Kikumoto. M., and Nakahara, E. 2011. Behavior of ground 
and response of existing foundation due to tunneling. Soils and Foundations, 51(3), 395 409.

Wayne, M. H., Han, J., and Akins, K. 1998. The design of geosynthetic reinforced foundations. Geosynthetics in foundation reinforcement and erosion control systems, ASCE Geotechnical Special Publication No. 76, Reston, USA, 1-18.

Yetimoglu, T., Wu, J., and Saglamer, A. 1994. Bearing Capacity of Rectangular Footings on Geogrid - Reinforced Sand. J. of Geotechnical Engineering, 120(12), 2083-2099. 


\section{List of Figures and Tables}

Fig. 1. Schematic diagram of the laboratory model apparatus

Fig. 2. Model of foundation

Fig. 3. Typical finite element mesh

Fig. 4. Results of the biaxial test and the analysis of the aluminum rod mass

Fig. 5. Computed results of the joint element

Fig. 6. Vertical load vs. vertical displacement for different reinforcement installation depths

Fig. 7. Computed bending moment and axial force for different reinforcement installation depths

Fig. 8. Deviatoric strain distribution for different reinforcement installation depths

Fig. 9. Vertical load vs. vertical displacement for different reinforcement lengths

Fig. 10. Computed bending moment and axial force for different reinforcement lengths

Fig. 11. Deviatoric strain distribution for different reinforcement lengths

Fig. 12. Vertical load vs. vertical displacement: smooth reinforcement

Fig. 13. Computed bending moment and axial force: smooth reinforcement

Fig. 14. Deviatoric strain distribution: smooth reinforcement

Fig. 15. Observed vertical load vs. vertical displacement for concentric loading: Series 2

Fig. 16. Vertical load vs. vertical displacement for concentric loading: numerical analyses

Fig. 17. Computed bending moment and axial force for different reinforcement lengths

Fig. 18. Distribution of deviatoric strain: fixed end $(\mathrm{D} / \mathrm{B}=1 / 4)$ : Series 2

Fig. 19. Vertical load vs. vertical displacement for concentric loading: Series 3

Fig. 20. Deviatoric strain distributions - concentric loading: Series 3

Fig. 21. Vertical load vs. vertical displacement for eccentric loading: Series 3

Fig. 22. Rotation angle vs. load for eccentric loading - eccentric loading: Series 3

Fig. 23. Deviatoric strain distributions: eccentric loading

Table 1. Test patterns: Series 1 
Table 2. Test patterns: Series 2

Table 3. Test patterns: Series 3

Table 4. Values of the material parameters for the aluminum rod masses 


\section{APPENDIX A1}

\section{Modelling of Elastoplastic Joint Element}

The behavior of interface between two different materials is uniform before reaching the ratio of tangential $\left(P_{s}\right)$ and normal force $\left(P_{n)}\right.$ per unit length $\left(P_{s} / P_{n)}\right.$ to the tangent of the maximum friction angle $(\tan \delta)$ of the interface (Nakai, 1985) which is shown in Fig.A1. Once $P_{s} / P_{n}$ reaches to $\tan \delta$, slip will occur at the boundary and the value of $P_{s} / P_{n}$ will be $\tan \delta$ onward. Therefore, the stiffness matrix of joint element should be formed which can consider this phenomenon to be consistent with the behavior of the joint element.

Increment of shearing stress $d P_{s}$, normal stress $d P_{n}$ of a joint element can be related with the increment of relative shearing strain $d w_{s}$, and relative normal strain $d w_{n}$, by the following equation.

$$
\left\{\begin{array}{l}
d P_{s} \\
d P_{n}
\end{array}\right\}=\left[D_{j}\right]\left\{\begin{array}{l}
d w_{s} \\
d w_{n}
\end{array}\right\}=\left[\begin{array}{ll}
k_{11} & k_{12} \\
k_{21} & k_{22}
\end{array}\right]\left\{\begin{array}{l}
d w_{s} \\
d w_{n}
\end{array}\right\}(\mathrm{A} 1)
$$

Wheere, $\left[D_{j}\right]$ is the strain-displacement matrix of the joint element. As shown in Fig.A1, slip does not occur when $P_{s} / P_{n}<\tan \delta$ and it occurs when $P_{s} / P_{n} \geq \tan \delta$.

\section{Case1: $P_{s} / P_{n} \leq \tan \delta$}

When $P_{s} / P_{n}<\tan \delta$, there is almost no displacement at the boundary surface both in shearing and normal directions. Therefore, the relative displacements of joint element $\left(w_{s}, w_{n}\right)$ can be considered as infinitesimal elastic displacement. The formulation for this condition can be described as,

$$
\begin{aligned}
& d w_{s}=d w_{s}^{e}=\frac{1}{k_{s}} d P_{s} \\
& d w_{n}=d w_{n}^{e}=\frac{1}{k_{n}} d P_{n}
\end{aligned}
$$

Where $k_{n}$ is the unit stiffness across and $k_{s}$, the unit stiffness along the joint element. The values of $k_{s}$ and $k_{n}$ are taken as large positive numbers. 
The strain-displacement matrix $\left[D_{j}\right]$ then can be obtained by combining equations $(A 1),(A 2)$ and $(A 3)$ as,

$$
\left\{\begin{array}{l}
d P_{s} \\
d P_{n}
\end{array}\right\}=\left[\begin{array}{cc}
k_{s} & 0 \\
0 & k_{n}
\end{array}\right]\left\{\begin{array}{l}
d w_{s} \\
d w_{n}
\end{array}\right\}=\left[D_{j}\right]\left\{\begin{array}{l}
d w_{s} \\
d w_{n}
\end{array}\right\}
$$

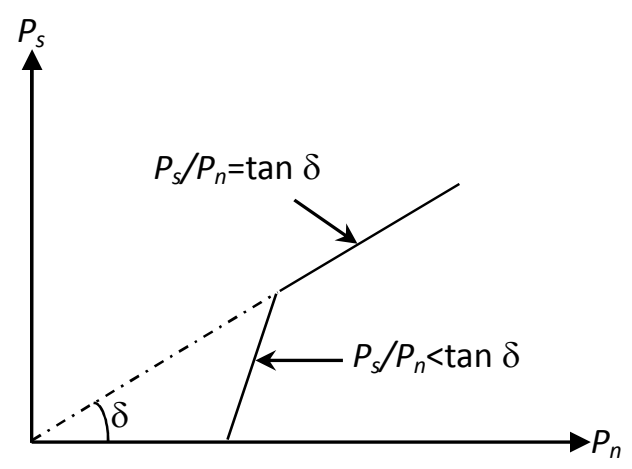

Fig. A1: Relation between $P_{s} / P_{n}$ and $\tan \delta$ of discontinuous surface

\section{Case 2: $P_{\underline{S}} / P_{\underline{n}} \underline{\underline{\tan \delta}}$}

In this condition, the normal displacement of the boundary is the same as Case 1 i.e. equation (A3). However, plastic shearing displacement $w_{s}^{p}$ occurs after $P_{s} / P_{n}$ reaches to tan $\delta$ as shown in Fig.A1. The relation of $w_{s}^{p}$ and $P_{s} / P_{n}$ can be written as,

$$
\frac{P_{s}}{P_{n}}=\xi w_{s}^{p}+\tan \delta
$$

Where $\xi$ is a positive multiplier whose value is very close to zero, therefore, $\tan \delta$ dominates in the right side of equation (A5), so, this condition can be approximated as a nearly perfectly plastic condition as shown in Fig. A2. 


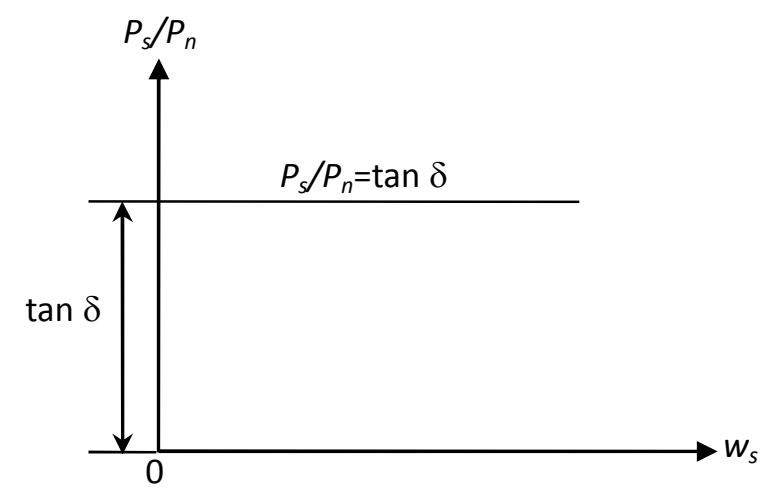

Fig. A2: Relation between $P_{s} / P_{n}$ and $w_{s}$ in a perfectly plastic condition

Differentiating and rearranging equation (A5), $w_{s}^{p}$ can be expressed by the following equation.

$$
d w_{s}^{p}=\frac{1}{\xi} d\left(\frac{P_{s}}{P_{n}}\right)=\frac{1}{\xi} d\left(\frac{1}{P_{n}} d P_{s}-\frac{P_{s}}{P_{n}^{2}} d P_{n}\right)(\text { A6) }
$$

And the total shearing displacement can be expressed as

$$
d w_{s}=d w_{s}^{e}+d w_{s}^{p}=\left(\frac{1}{k_{s}}+\frac{1}{\xi P_{n}}\right) d P_{s}-\frac{P_{s}}{\xi P_{n}^{2}} d P_{n}(\mathrm{~A} 7)
$$

Combining equations (A3) and (A7) the relation of the displacement increment and stress increment of the joint element can be expressed as

$$
\left\{\begin{array}{l}
d w_{s} \\
d w_{n}
\end{array}\right\}=\left[\begin{array}{cc}
\frac{1}{k_{s}}+\frac{1}{\xi P_{n}} & -\frac{P_{s}}{\xi P_{n}^{2}} \\
0 & \frac{1}{k_{n}}
\end{array}\right]\left\{\begin{array}{l}
d P_{s} \\
d P_{n}
\end{array}\right\}
$$

Therefore, the strain-displacement matrix of the joint element $\left[D_{j}\right]$ can be expressed by the following equation.

$$
\left\{\begin{array}{l}
d P_{s} \\
d P_{n}
\end{array}\right\}=\left[\begin{array}{cc}
\frac{\xi k_{s} P_{n}}{k_{s}+\xi P_{n}} & \frac{k_{s} k_{n} P_{s}}{k_{s} P_{n}+\xi P_{n}^{2}} \\
0 & k_{n}
\end{array}\right]\left\{\begin{array}{l}
d w_{s} \\
d w_{n}
\end{array}\right\}=\left[D_{j}\right]\left\{\begin{array}{l}
d w_{s} \\
d w_{n}
\end{array}\right\}
$$




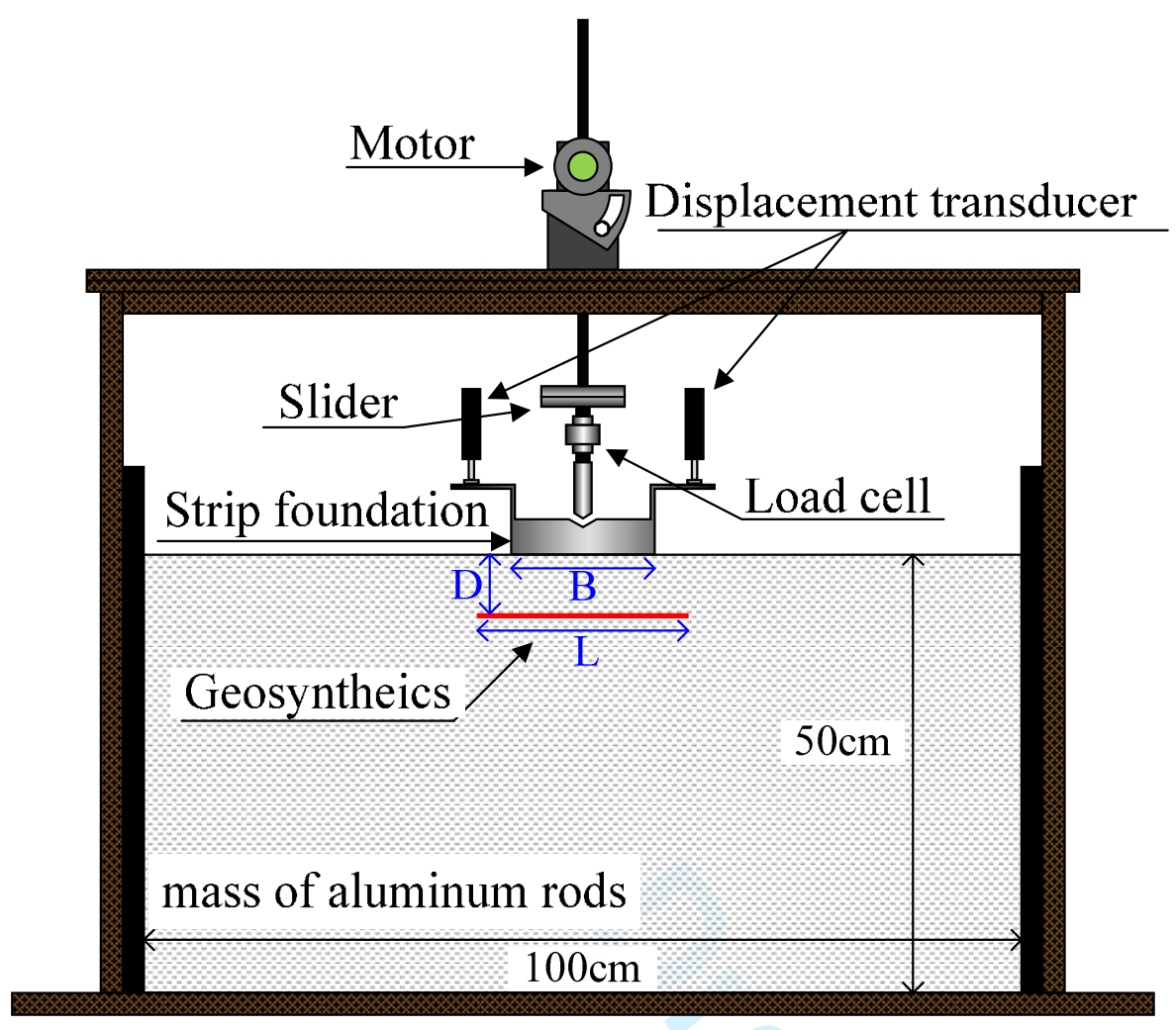

Fig. 1. Schematic diagram of the laboratory model apparatus 


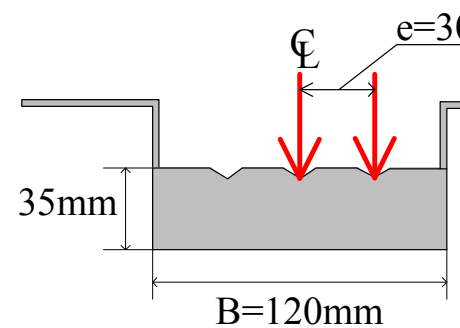

(a)

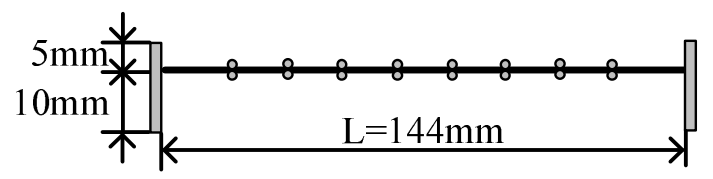

(b)

Fig. 2. (a) Model of foundation, (b) model of reinforcement material 


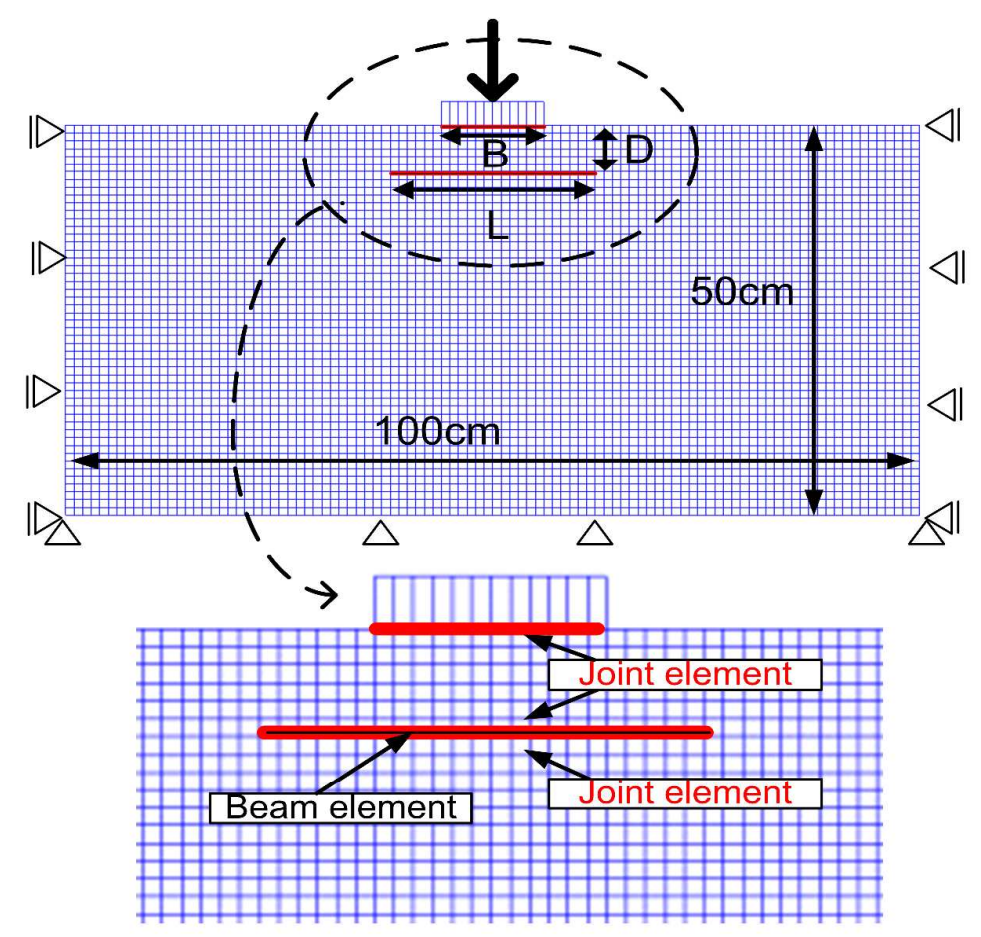

Fig. 3. Typical finite element mesh 


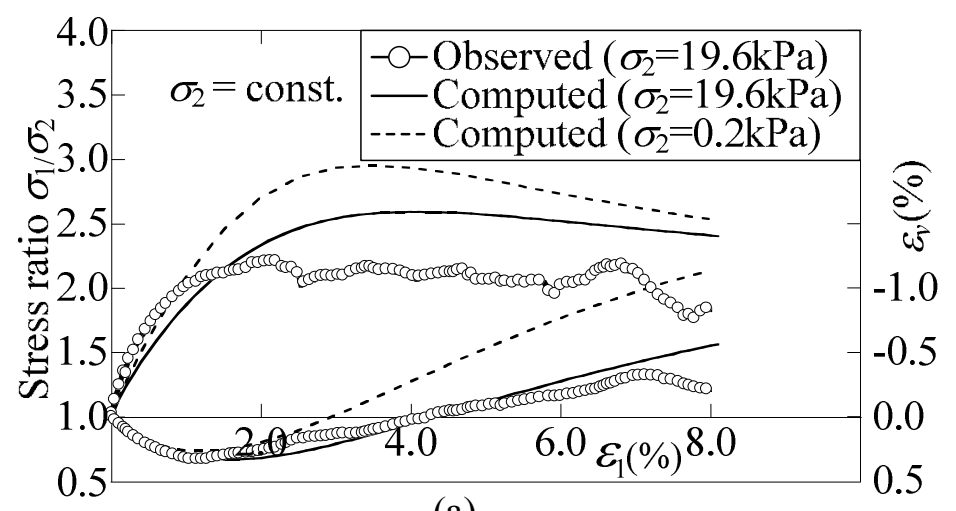

(a)

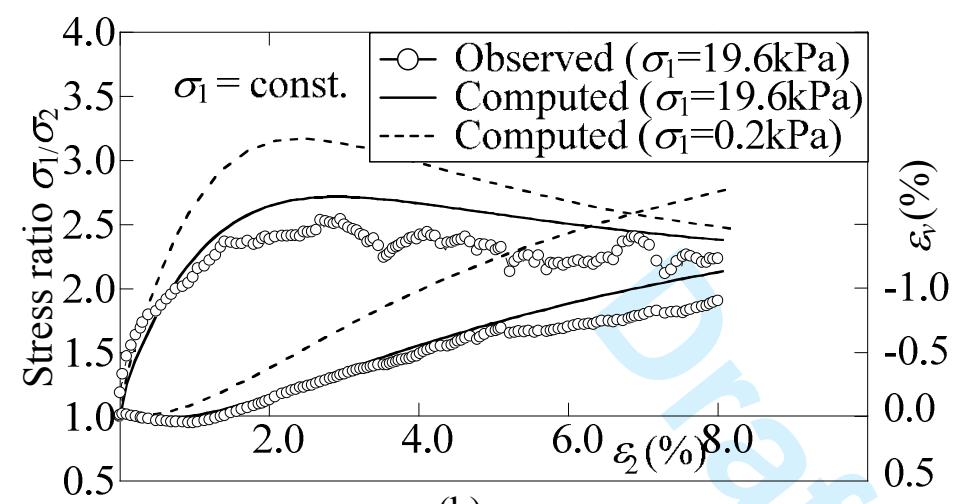

(b)

Fig. 4. Results of the biaxial test and the analysis of the aluminum rod mass - (a) Under constant minor stress, (b) Under constant major stress 


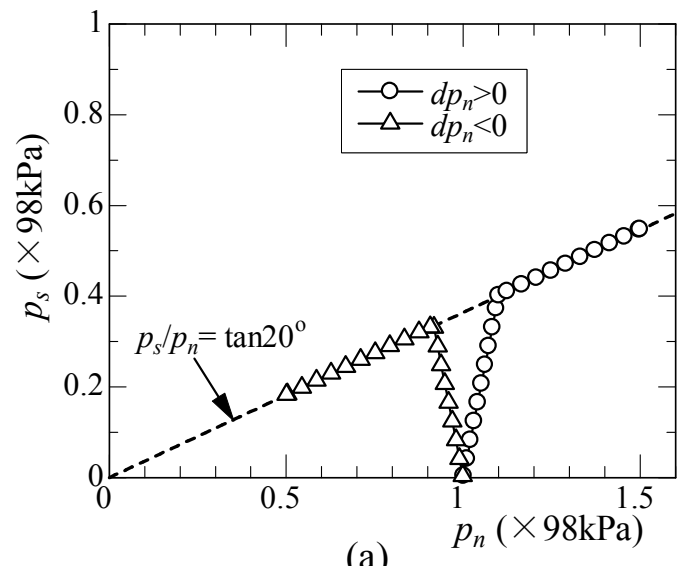

(a)

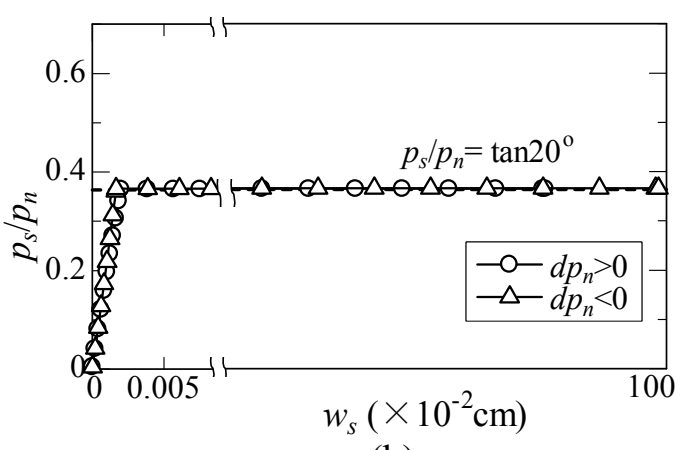

(b)

Fig. 5. Computed results of the joint element - (a) Tangential force vs. normal force, (b) Ratio of forces vs. relative displacement 

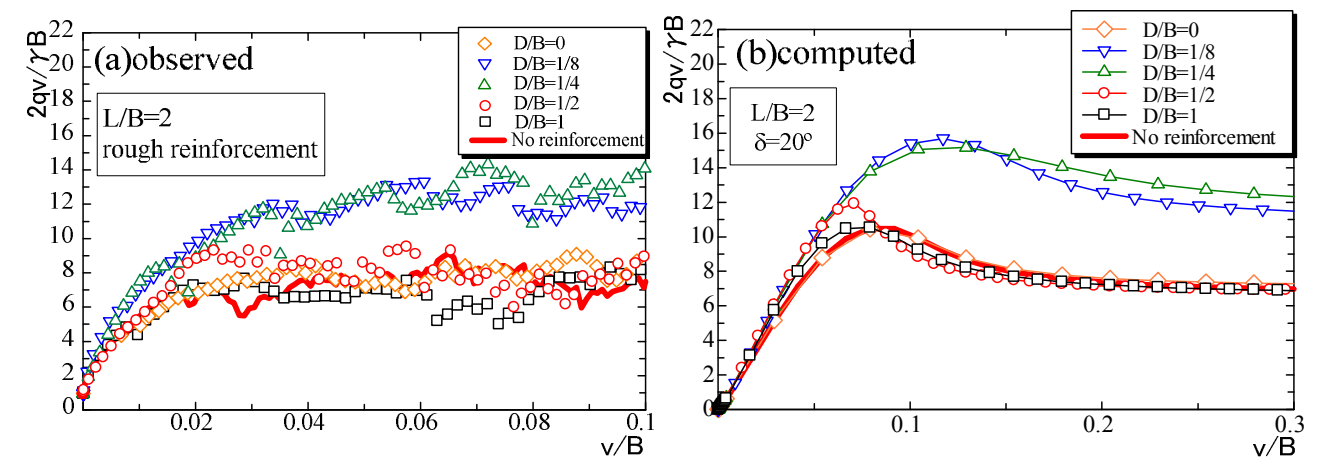

Fig. 6. Vertical load vs. vertical displacement for different reinforcement installation depths 


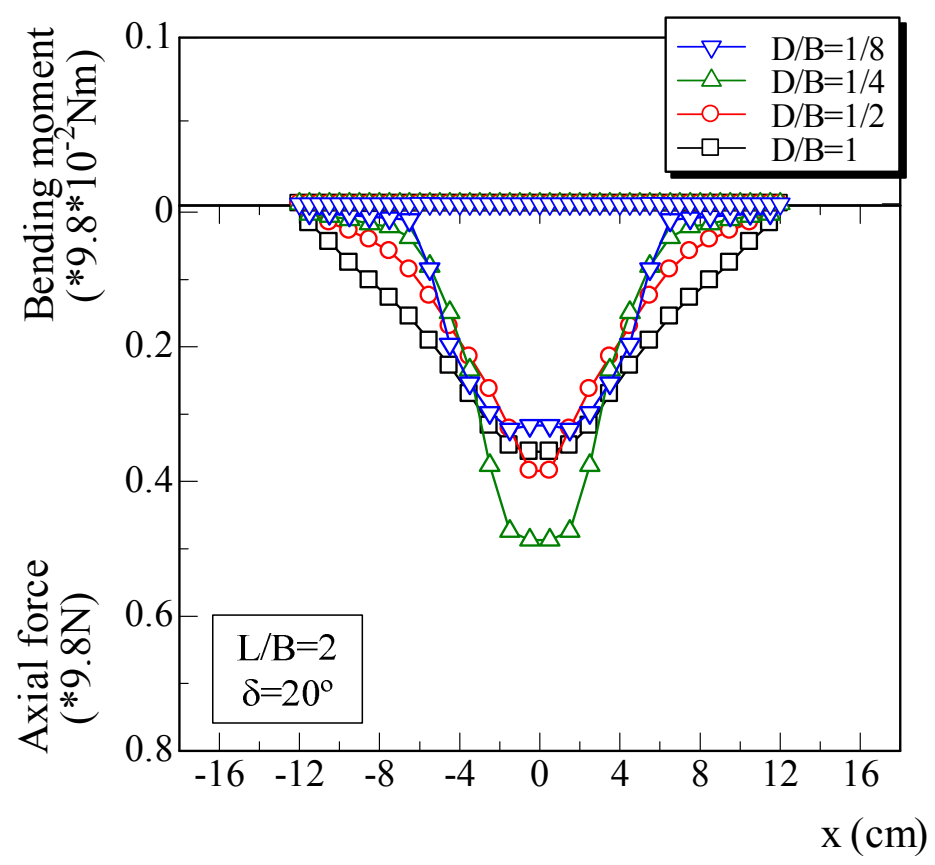

Fig. 7. Computed bending moment and axial force for different reinforcement installation depths 


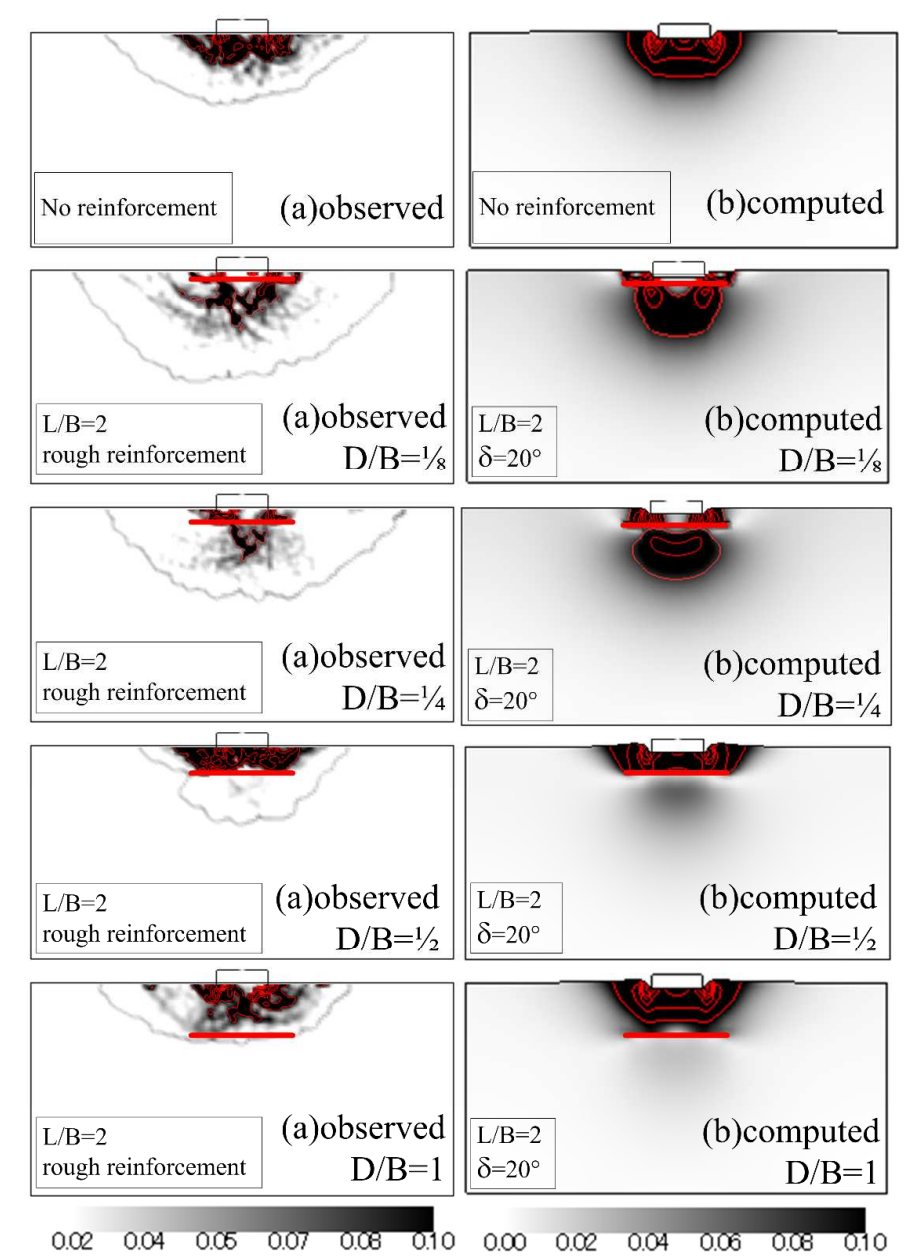

Fig. 8. Deviatoric strain distribution for different reinforcement installation depths 

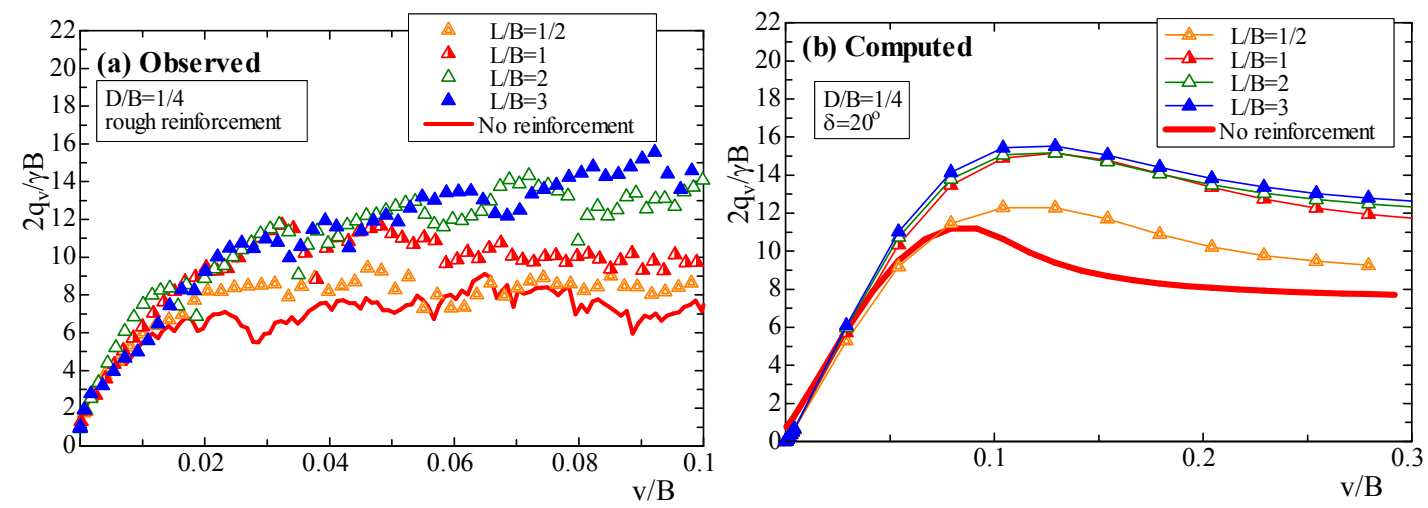

Fig. 9. Vertical load vs. vertical displacement for different reinforcement lengths 


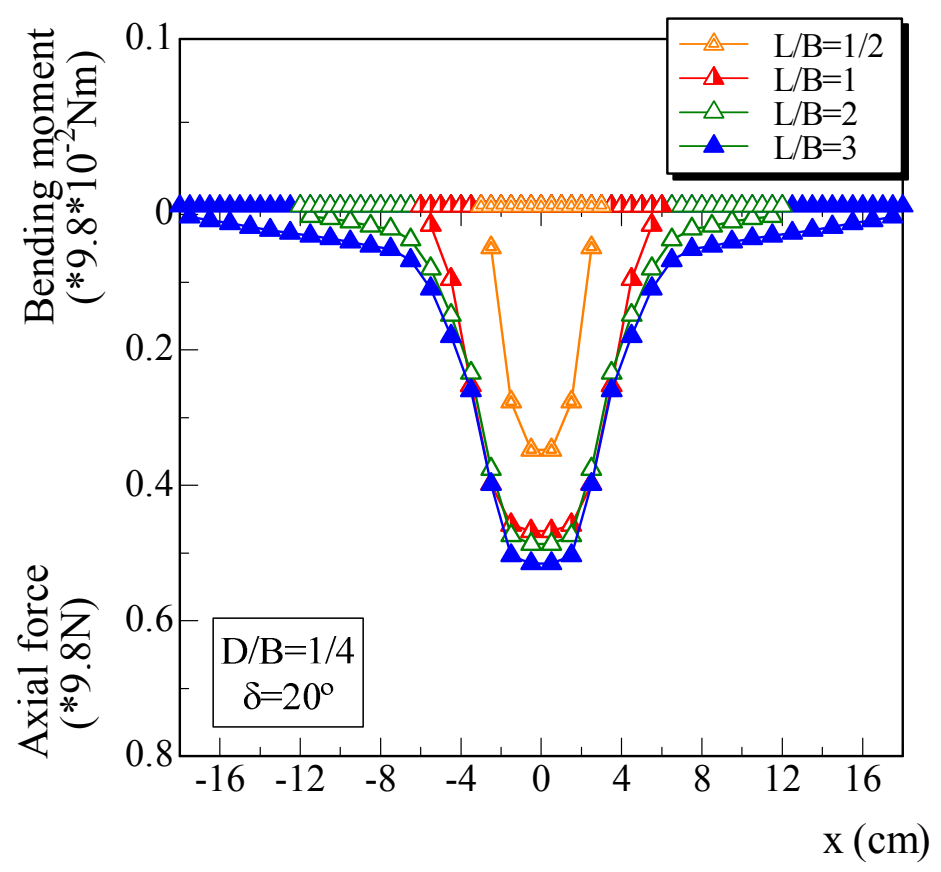

Fig. 10. Computed bending moment and axial force for different reinforcement lengths 

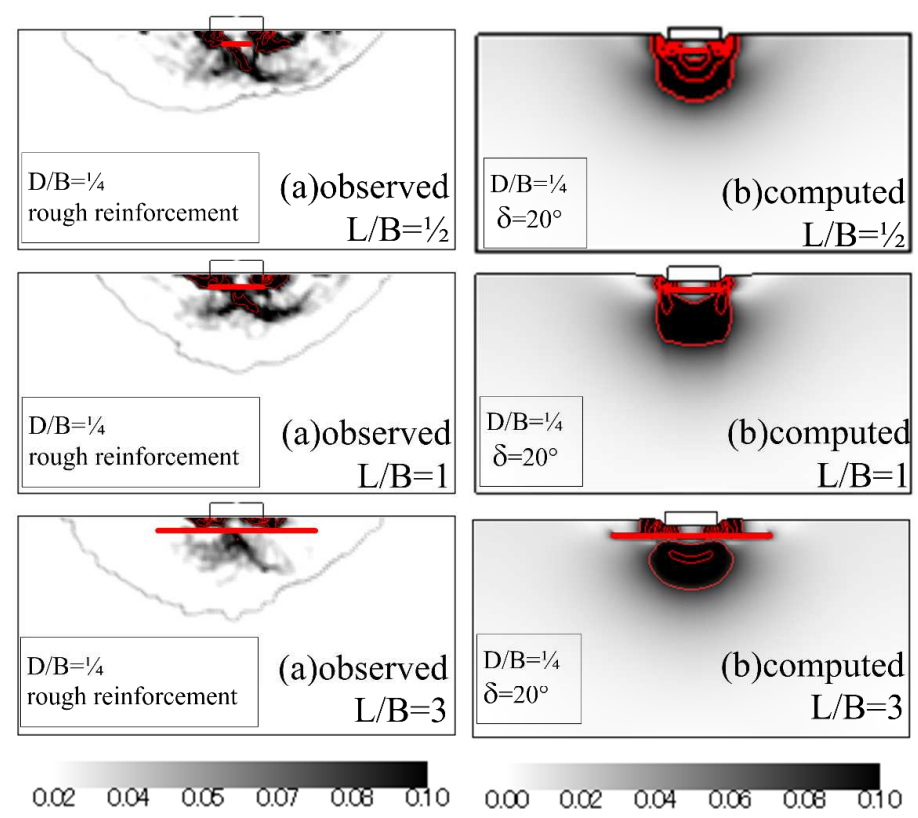

Fig. 11. Deviatoric strain distribution for different reinforcement lengths 

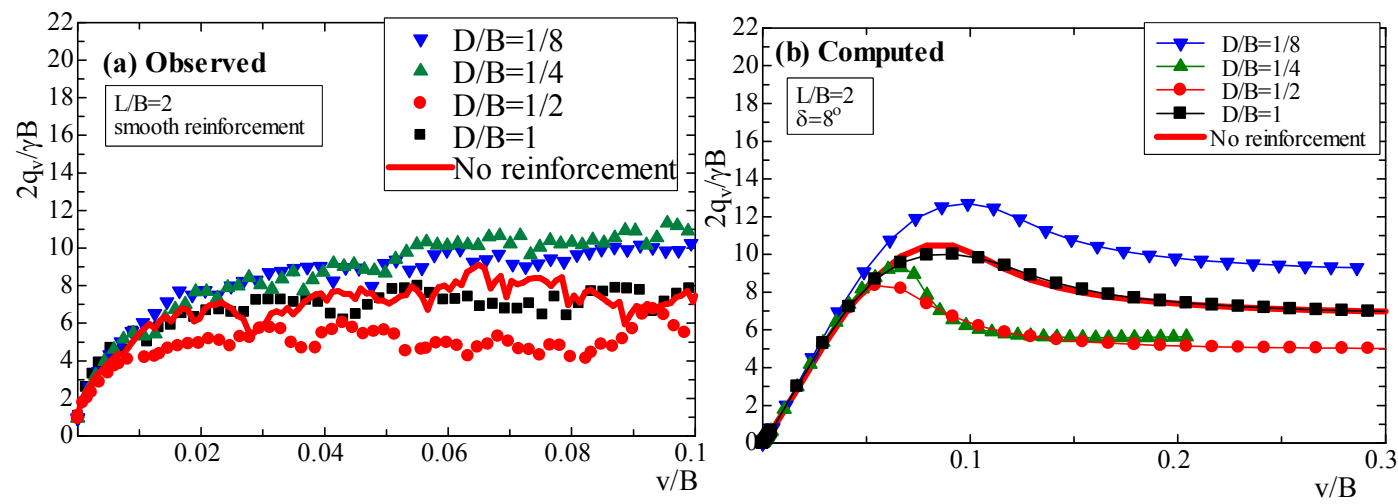

Fig. 12. Vertical load vs. vertical displacement: smooth reinforcement 


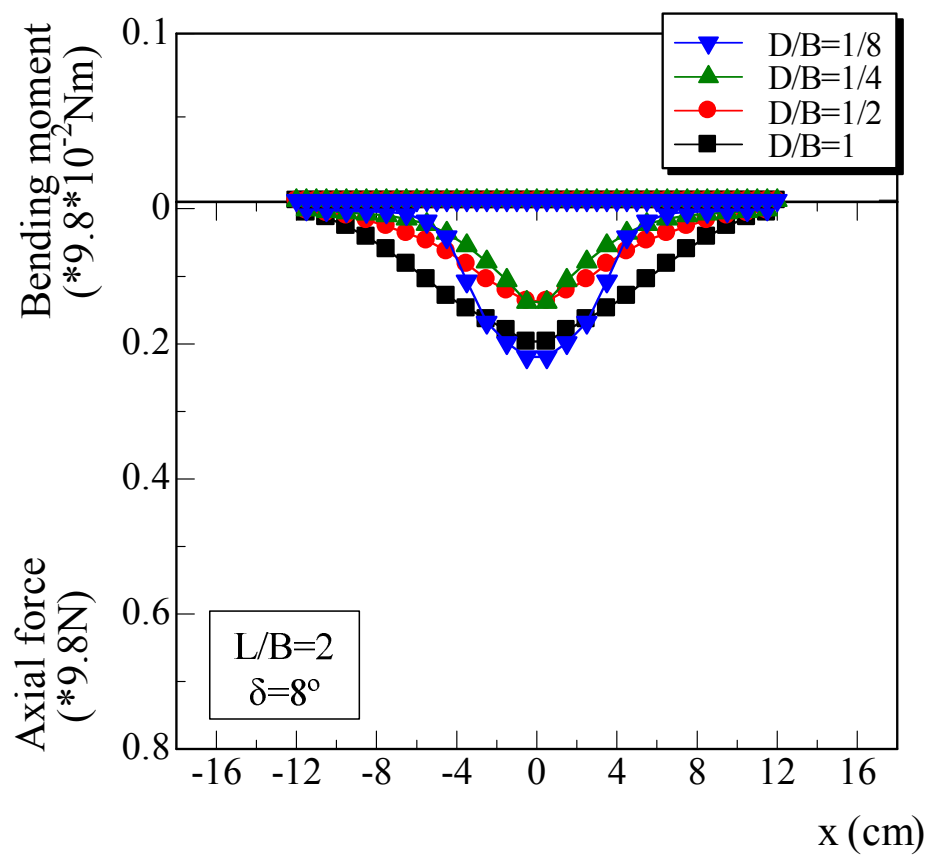

Fig. 13. Computed bending moment and axial force: smooth reinforcement 

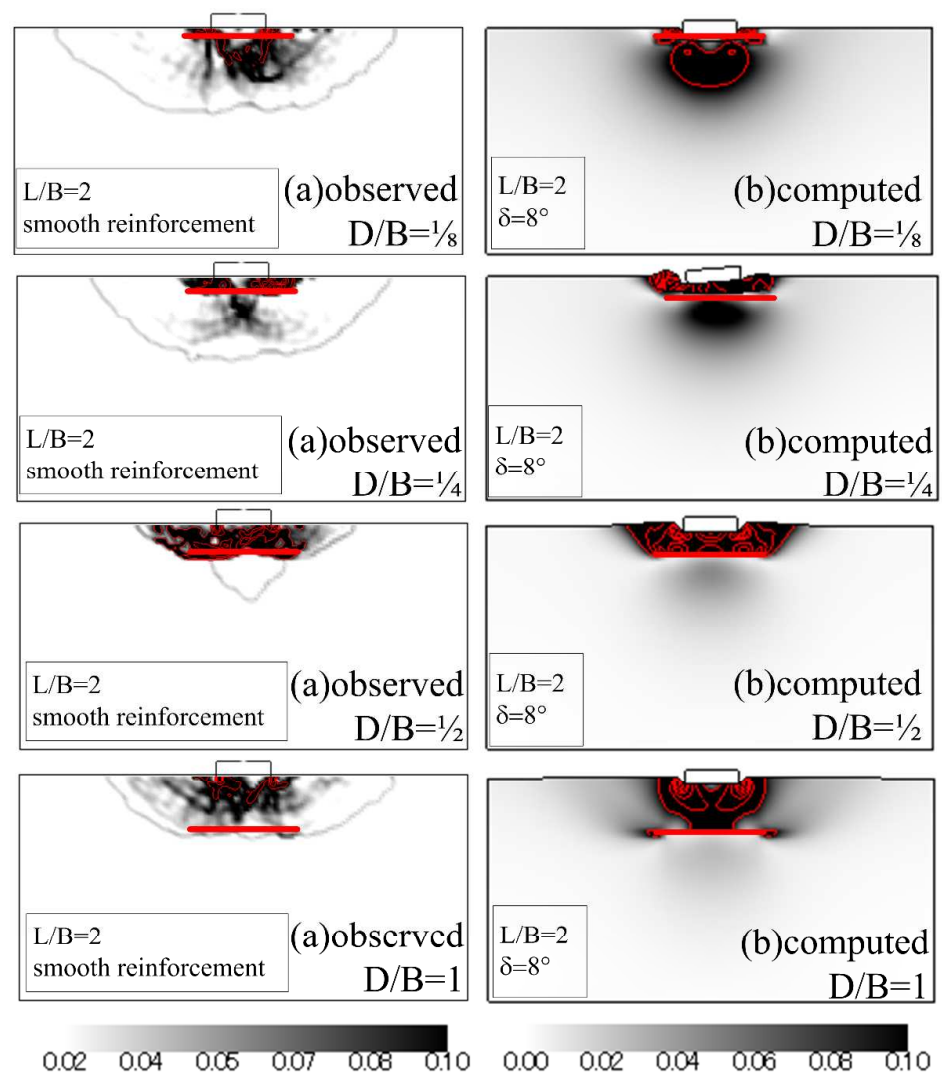

Fig. 14. Deviatoric strain distribution: smooth reinforcement 

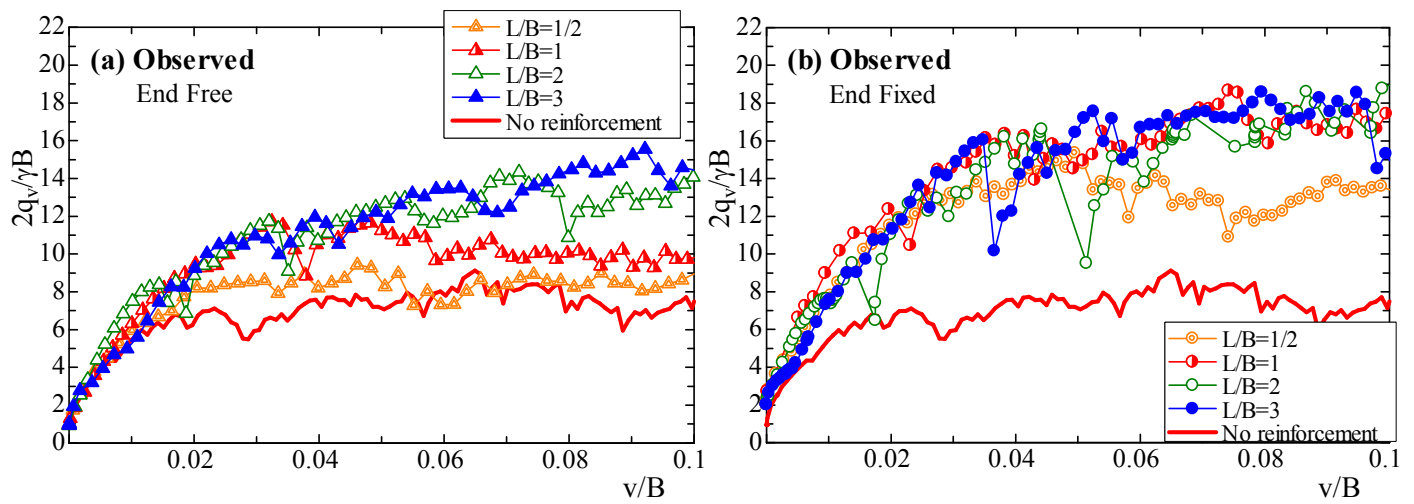

Fig. 15. Observed vertical load vs. vertical displacement for concentric loading: Series 2 

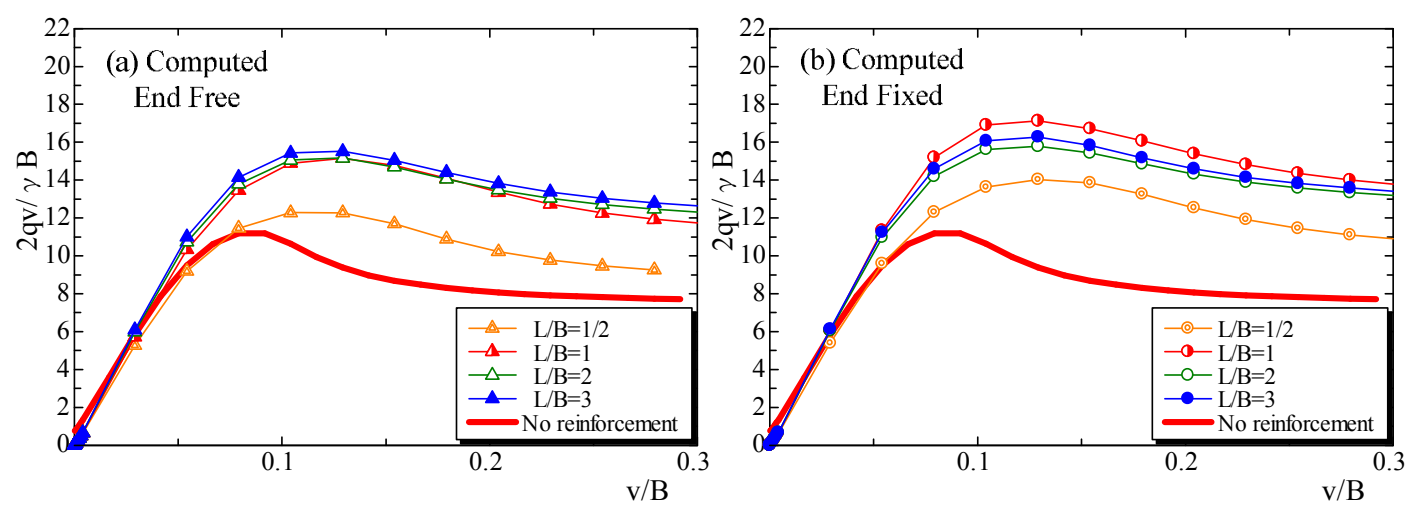

Fig. 16. Vertical load vs. vertical displacement for concentric loading: numerical analyses 

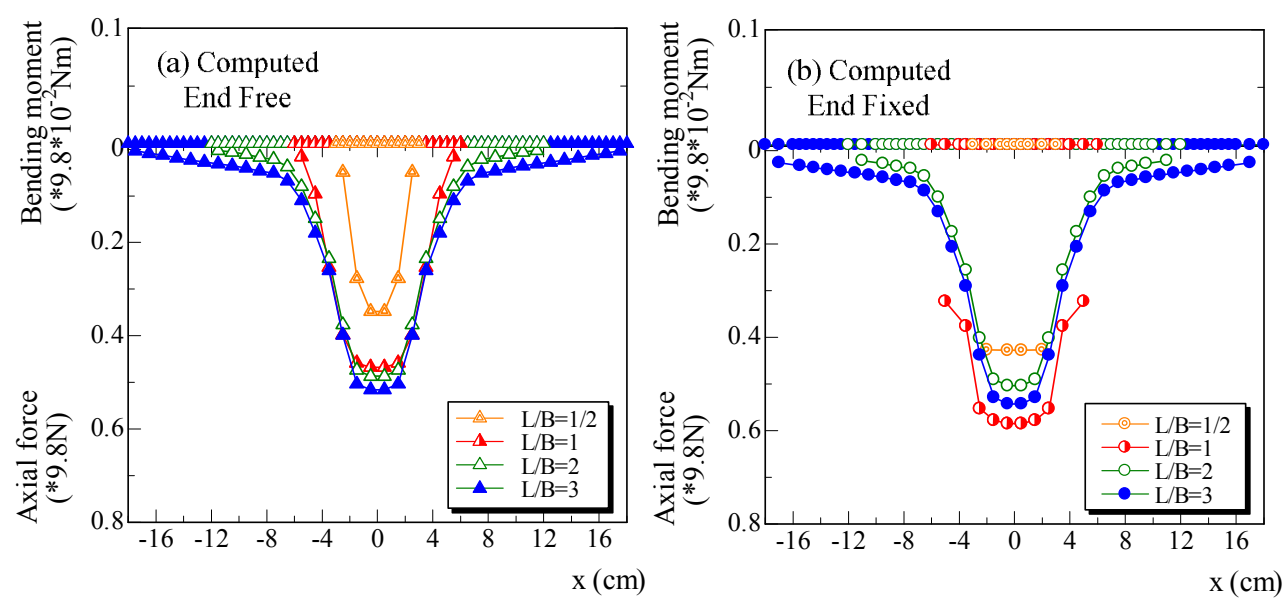

Fig. 17. Computed bending moment and axial force for different reinforcement lengths 


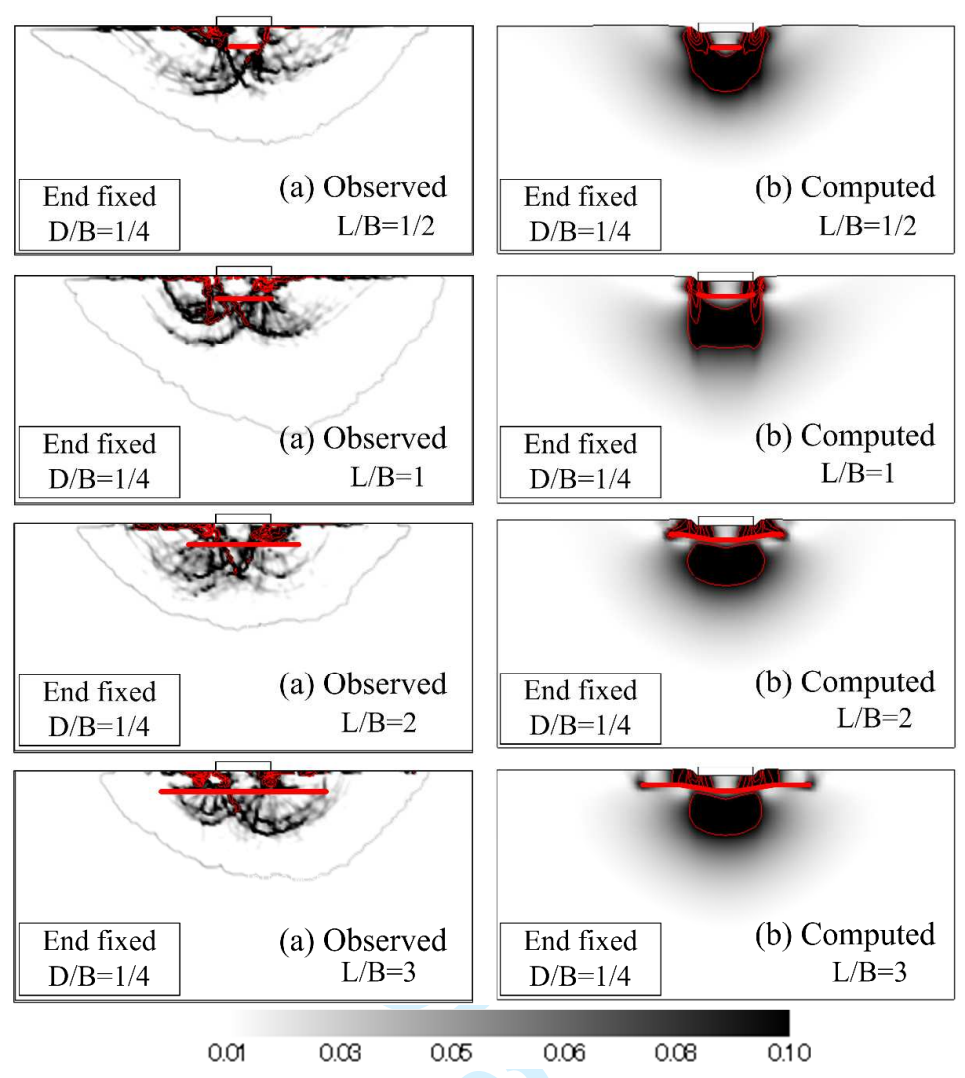

Fig. 18. Distribution of deviatoric strain: fixed end $(D / B=1 / 4)$ : Series 2 

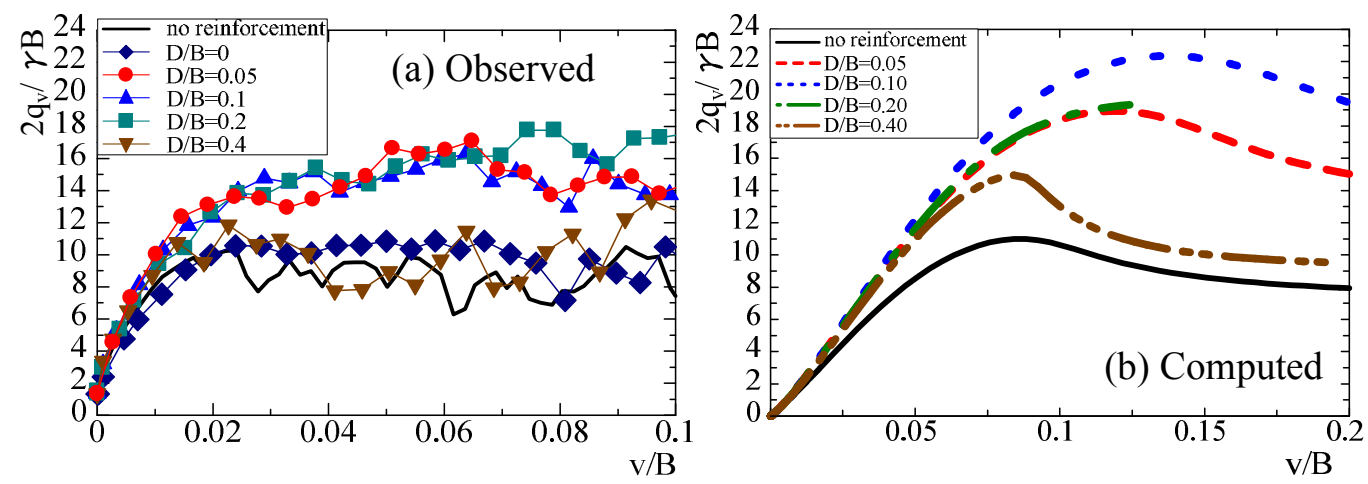

Fig. 19. Vertical load vs. vertical displacement for concentric loading: Series 3 


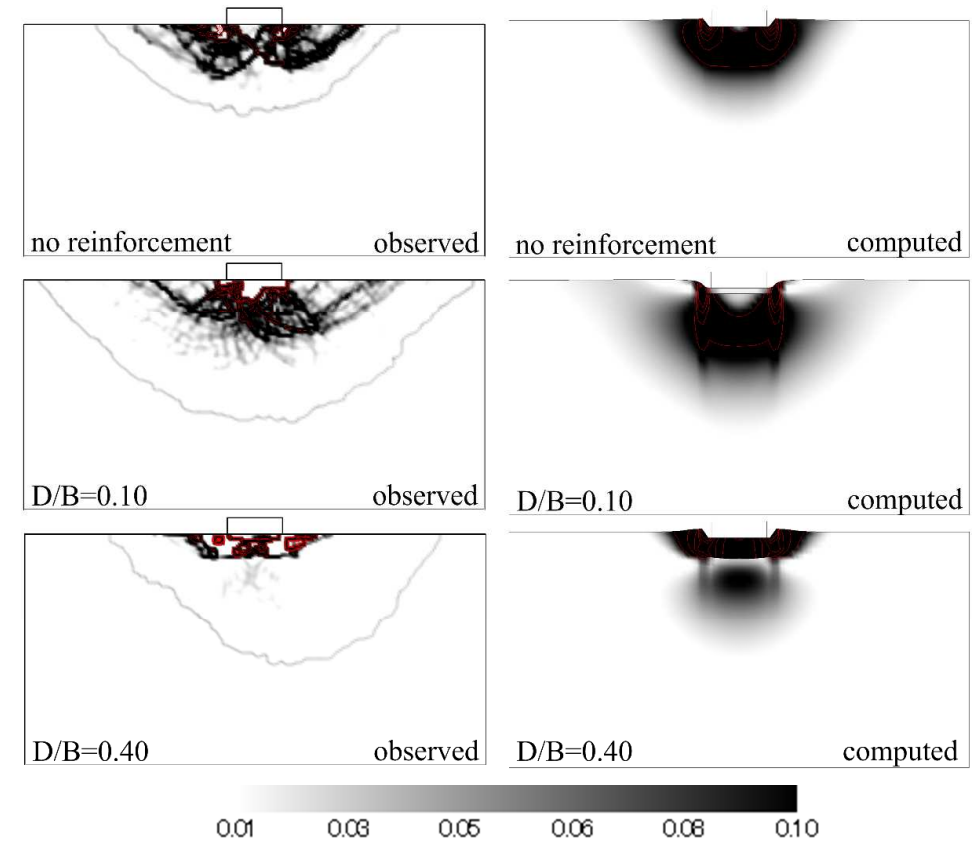

Fig. 20. Deviatoric strain distributions - concentric loading: Series 3 

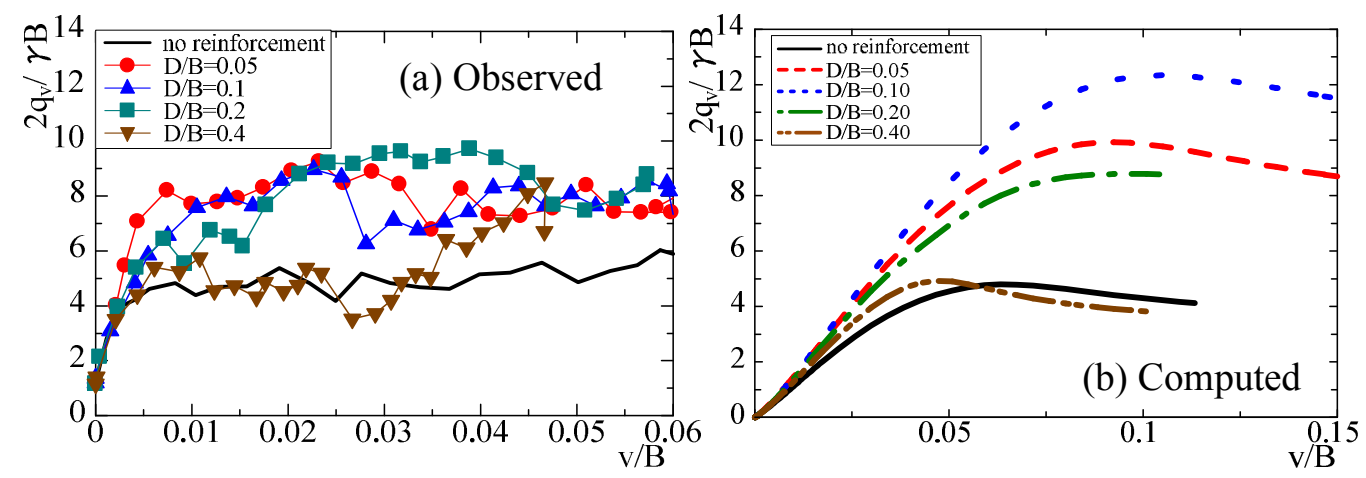

Fig. 21. Vertical load vs. vertical displacement for eccentric loading: Series 3 

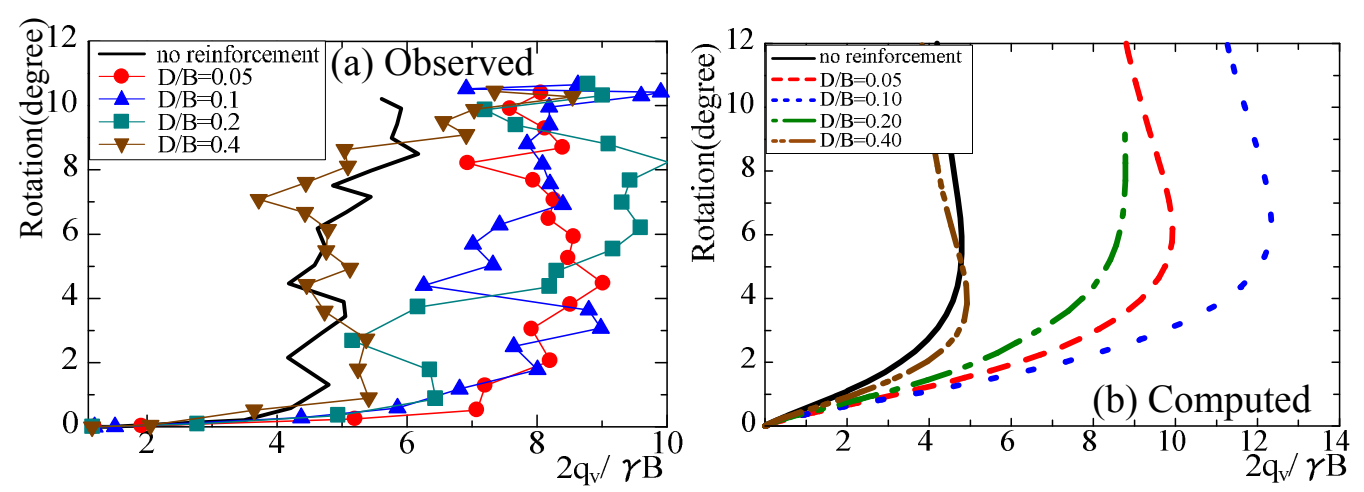

Fig. 22. Rotation angle vs. load for eccentric loading - eccentric loading: Series 3 


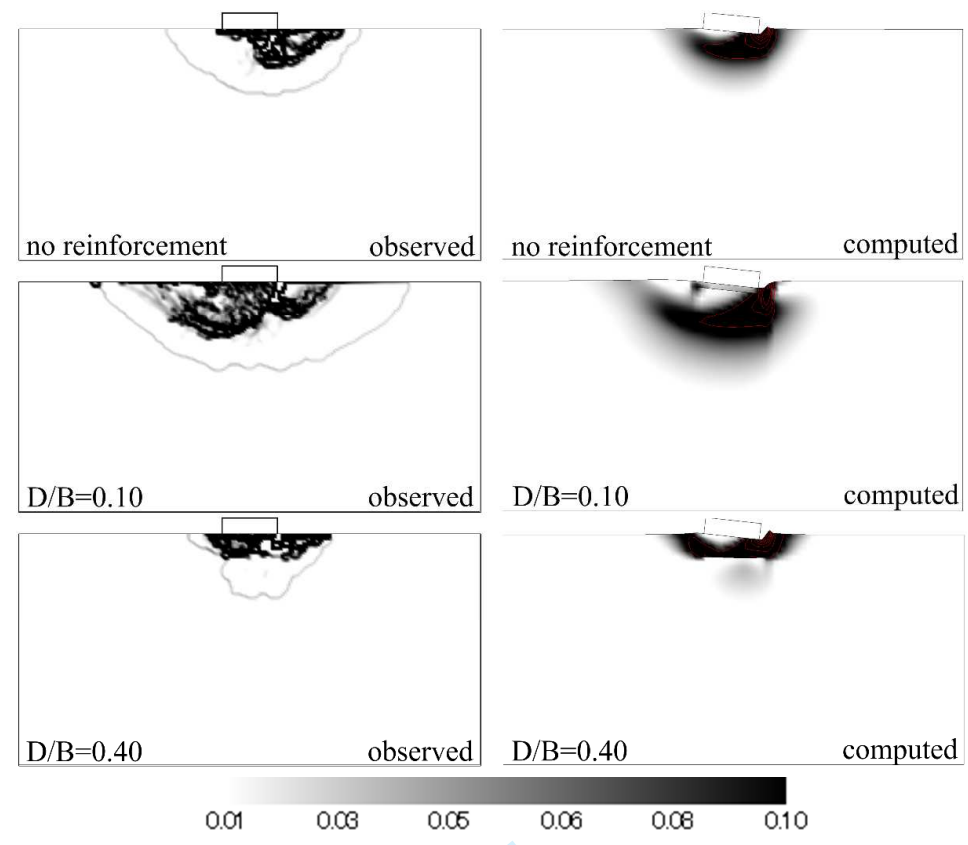

Fig. 23. Deviatoric strain distributions: eccentric loading 
Table 1. Test patterns: Series 1

\begin{tabular}{|c|c|c|c|c|c|c|}
\hline$\delta$ & $\mathrm{L} / \mathrm{B}$ & \multicolumn{5}{|c|}{$\mathrm{D} / \mathrm{B}$} \\
\hline \multirow{4}{*}{$\begin{array}{l}\text { Rough reinforcement } \\
\delta=20^{\circ}\end{array}$} & $1 / 2$ & \multicolumn{5}{|c|}{$1 / 4$} \\
\hline & 1 & \multicolumn{5}{|c|}{$1 / 4$} \\
\hline & 2 & 0 & $1 / 8$ & $1 / 4$ & $1 / 2$ & 1 \\
\hline & 3 & \multicolumn{5}{|c|}{$1 / 4$} \\
\hline $\begin{array}{l}\text { Smooth reinforcement } \\
\delta=8^{0}\end{array}$ & 2 & - & $1 / 8$ & $1 / 4$ & $1 / 2$ & 1 \\
\hline \multicolumn{7}{|l|}{ No reinforcement } \\
\hline
\end{tabular}

Table 2. Test patterns: Series 2

\begin{tabular}{|c|c|c|c|c|}
\hline \multicolumn{5}{|c|}{ Pattern } \\
\hline $\begin{array}{c}\text { Depth of } \\
\text { reinforcement } \\
\text { D/B=1/4 }\end{array}$ & \multicolumn{4}{|c|}{ Length of reinforcement $\mathrm{L} / \mathrm{B}$} \\
\hline End fixed & $1 / 2$ & 1 & 2 & 3 \\
\hline
\end{tabular}

Table 3. Test patterns: Series 3

\begin{tabular}{|c|c|c|c|c|c|}
\hline \multicolumn{5}{|c|}{ Pattern ( Length of reinforcement $\mathrm{L} / \mathrm{B}=1.2$ ) } \\
\cline { 2 - 6 } & $\mathrm{D} / \mathrm{B}=0$ & $\mathrm{D} / \mathrm{B}=0.05$ & $\mathrm{D} / \mathrm{B}=0.1$ & $\mathrm{D} / \mathrm{B}=0.2$ & $\mathrm{D} / \mathrm{B}=0.4$ \\
\hline $\begin{array}{c}\text { Concentric } \\
\text { Loading }\end{array}$ & $\bigcirc$ & $\bigcirc$ & $\bigcirc$ & $\bigcirc$ & $\bigcirc$ \\
\hline $\begin{array}{c}\text { Eccentric } \\
\text { Loading }\end{array}$ & $\mathrm{O}$ & $\bigcirc$ & $\bigcirc$ & $\bigcirc$ & $\bigcirc$ \\
\hline
\end{tabular}

Table 4. Values of the material parameters for the aluminum rod masses

\begin{tabular}{|c|c|c|}
\hline$\lambda$ & 0.008 & \multirow{5}{*}{$\begin{array}{l}\text { Same parameters as Cam } \\
\text { Clay model }\end{array}$} \\
\hline$\kappa$ & 0.004 & \\
\hline $\begin{array}{l}N\left(e_{N C} \text { at } p=98 \mathrm{kPa}\right. \\
\& q=0 \mathrm{kPa})\end{array}$ & 030 & \\
\hline$R_{C S}=\left(\sigma_{1} / \sigma_{3}\right)_{\mathrm{CS}(\text { comp. })}$ & 1.80 & \\
\hline$v_{\mathrm{e}}$ & 0.20 & \\
\hline$\beta$ & 1.20 & $\begin{array}{l}\text { Shape of yield surface (same } \\
\text { as original Cam clay if } \beta=1 \text { ) }\end{array}$ \\
\hline$a^{*}$ & 1300 & $\begin{array}{l}\text { Influence of density and } \\
\text { confining pressure }\end{array}$ \\
\hline
\end{tabular}

